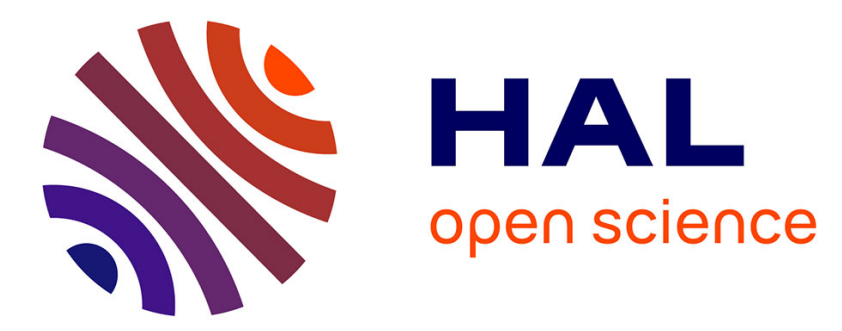

\title{
Downscaling of daily precipitation with a stochastic weather generator for the subtropical region in South China
}

\author{
Y. D. Chen, X. Chen, C.-Y. Xu, Q. Shao
}

\section{- To cite this version:}

Y. D. Chen, X. Chen, C.-Y. Xu, Q. Shao. Downscaling of daily precipitation with a stochastic weather generator for the subtropical region in South China. Hydrology and Earth System Sciences Discussions, 2006, 3 (3), pp.1145-1183. hal-00298717

\section{HAL Id: hal-00298717 https://hal.science/hal-00298717}

Submitted on 27 Jun 2006

HAL is a multi-disciplinary open access archive for the deposit and dissemination of scientific research documents, whether they are published or not. The documents may come from teaching and research institutions in France or abroad, or from public or private research centers.
L'archive ouverte pluridisciplinaire HAL, est destinée au dépôt et à la diffusion de documents scientifiques de niveau recherche, publiés ou non, émanant des établissements d'enseignement et de recherche français ou étrangers, des laboratoires publics ou privés. 
Hydrol. Earth Syst. Sci. Discuss., 3, 1145-1183, 2006 www.hydrol-earth-syst-sci-discuss.net/3/1145/2006/

(C) Author(s) 2006. This work is licensed under a Creative Commons License.
Hydrology and Earth System Sciences Discussions

Papers published in Hydrology and Earth System Sciences Discussions are under open-access review for the journal Hydrology and Earth System Sciences

\section{Downscaling of daily precipitation with a stochastic weather generator for the subtropical region in South China}

Y. D. Chen ${ }^{1}$, X. Chen ${ }^{2}$, C.-Y. Xu ${ }^{3}$, and Q. Shao ${ }^{4}$

${ }^{1}$ Department of Geography and Resource Management, The Chinese University of Hong Kong, Shatin, Hong Kong, China

${ }^{2}$ State Key Laboratory of Hydrology-Water Resources and Hydraulic Engineering, Hohai University, Nanjing, China

${ }^{3}$ Department of Geosciences, University of Oslo, Norway

${ }^{4}$ CSIRO Mathematical and Information Sciences, Leeuwin Centre, 65 Broadway Road, Floreat Park, WA 6014, Australia

Received: 9 February 2006 - Accepted: 1 April 2006 - Published: 27 June 2006

Correspondence to: Y. D. Chen (ydavidchen@ cuhk.edu.hk)

HESSD

$3,1145-1183,2006$

Downscaling of daily precipitation

Y. D. Chen et al.

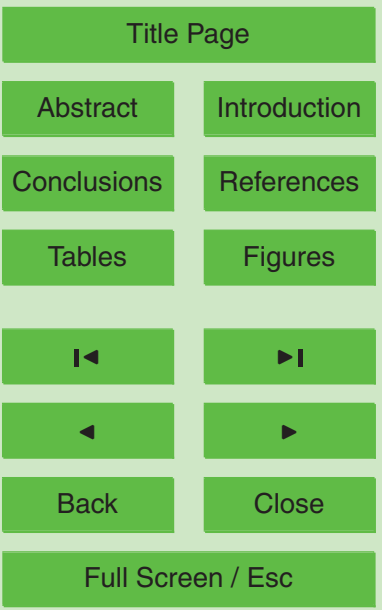

Printer-friendly Version

Interactive Discussion 


\section{Abstract}

Daily precipitation series at station or local scales is a critical input for rainfall-runoff modelling which, in turn, plays a vital role in the assessment of climate change impact on hydrologic processes and many other water resource studies. Future climate pro5 jected by General Circulation Models (GCMs) presents averaged values in large scales. Therefore, downscaling techniques are usually needed to transfer GCM-derived climate outputs into station-based values. In this study, a statistical downscaling model is investigated and its applicability in generating daily precipitation series is tested in the subtropical region of South China, which has not been investigated before. The model tion function for describing variation of wet-day precipitation amounts, and a statistical downscaling approach to transferring large-scale (in both space and time) future precipitation series from GCM climate change scenarios to station or local scales. A set of observed daily precipitation series of 32 years from 17 rainfall stations in and around 15 a grid of $2.5^{\circ}$ in latitude by $3.75^{\circ}$ in longitude in Guangdong province of China is used to evaluate the model accuracy and validate the downscaling results. The downscaled daily precipitation series and the extreme precipitation features (including maximum, maximum 3-day average and maximum 7-day average) are compared with the observed values. The results show that the proposed model is capable of reproducing the mean daily amount and model parameters of the daily precipitation series at station or local scales in the study region.

\section{Introduction}

Studies on the impact of global warming on the hydrological cycles and water resources in the future usually rely on climate change scenarios projected by General Circulation

\section{HESSD}

3, 1145-1183, 2006

Downscaling of daily precipitation

Y. D. Chen et al.

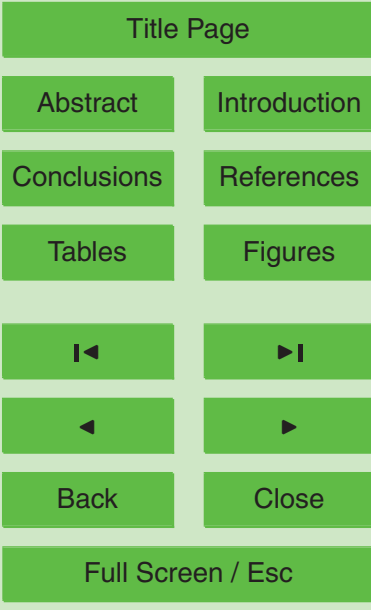

Printer-friendly Version

Interactive Discussion $10^{5} \mathrm{~km}^{2}$ ) cannot be applied directly in hydrologic studies at regional or basin scales. 
To derive local or station-based climate change scenarios from GCM output, a procedure called downscaling has been developed, tested and used through the efforts of many climatologists and hydrologists (e.g., Giorgi and Mearns, 1991; IPCC-TGCIA, 1999; Wilby and Wigley, 1997; IPCC, 2001; Wilby et al., 2000, 2002; Bardossy et al., 5 2002). Although the downscaling methods usually involve more than one technique and therefore tend to be hybrid in nature, they can generally be divided into three types (IPCC-TGCIA, 1999; IPCC, 2001). The simplest method is to interpolate values from the nearby GCM grids to the study area and is therefore called unintelligent downscaling. The second one called statistical downscaling applies various statistical 10 techniques to establish the relationships between observed local or station-based data and area-averaged meteorological or GCM scaled climate data. These sophisticated statistical downscaling methods include mainly regression methods, weather pattern approaches and stochastic weather generators (Wilby and Wigley, 1997; Xu, 1999). The third one called dynamic downscaling is implemented by running either a full GCM 15 at varying resolution across the globe with the highest resolution over the study region or a regional climate model (RCM) using GCM results as its boundary conditions (Wigley et al., 1990; Rummukainen et al., 2004).

Among the statistical downscaling methods, stochastic weather generator seems to be fairly simple but flexible and computationally economical (Wilks, 1999; Liao et al., 2004). It consists of three steps. Firstly, statistical models are established using observed daily precipitation at each site, and then used to generate daily precipitation series (e.g., Richardson, 1981; Wilks, 1989). Secondly, the historical relationship of the statistical parameters of the daily precipitation series between GCM-grid and local scales is established in order to transfer the parameter values from grid scale to local precipitation series projected from changed climate scenarios to local scale. Using the steps outlined above, the future daily precipitation series can be generated for each site.

Note that the GCM outputs are often in monthly rather than daily intervals in time.

HESSD

3, 1145-1183, 2006

Downscaling of daily precipitation

Y. D. Chen et al.

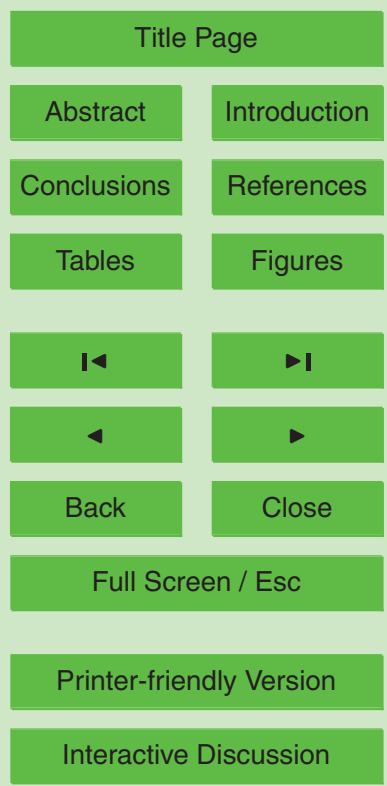

EGU 
It is very important to establish the parameter relationships between daily scale and monthly scale. In this paper, we discuss the possible adjustment of the statistical parameters of daily precipitation from monthly precipitations projected by HadCM2 which is a GCM developed and supported by the Hadley Centre for Climate Prediction and

5 Research, United Kingdom. In order to estimate the potential changes of daily parameters under the changed climate, some extreme features (including maximum, maximum 3-day average and maximum 7-day average) of the precipitation series generated by adjusted parameters are compared with the observed series at local scale.

Detailed modeling results are presented for the East River (Dongjiang) basin and 10 its surrounding areas in Guangdong province, a subtropical region of South China. Compared with the rich studies in the USA and European countries, few statistical downscaling exercises have been carried out in China (e.g., Liao et al., 2004), and no study has been reported in the rainfall rich regions in South China. This study will contribute to filling such a knowledge gap in this region.

\section{Study area and data}

The study area is a grid from $112.50^{\circ} \mathrm{E}$ to $116.25^{\circ} \mathrm{E}$ and $22.5^{\circ} \mathrm{N}$ to $25^{\circ} \mathrm{N}$, which is identical with one grid of HadCM2. As shown in Fig. 1, there are 17 meteorological stations located within or slightly outside of the grid. Each station has a 32-year (19591990) daily precipitation series. Situated in Guangdong province in South China, the study area is controlled by a subtropical monsoon climate which is characterized by two highly distintive wet and dry seasons. The majority of rainfall (around $80 \%$ ) occurs from April to September and the dry season kasts from October to March of the following year. Rainfall is mainly due to frontal activities from April to June. Typhoons bring large amounts of rainfall from June to September, particularly in the southern and coastal areas. The regional climate is hot during the long summer and the air temperatures are usually mild while cold weather (below $10^{\circ} \mathrm{C}$ ) dominates only occasionally under the influence of cold waves from North China. Table 1 presents the location, annual

HESSD

3, 1145-1183, 2006

Downscaling of daily precipitation

Y. D. Chen et al.

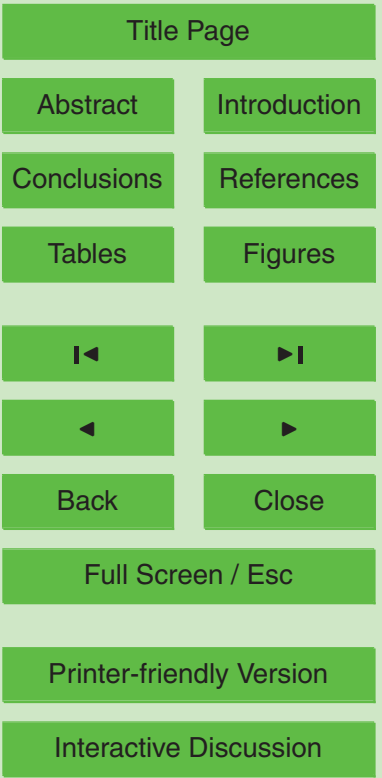

EGU 
mean precipitation and weight estimated from Thiessen polygons for computing the areal mean precipitation for the study area (i.e., the GCM grid).

HESSD

3, 1145-1183, 2006

\section{Downscaling of daily} precipitation

\section{Y. D. Chen et al.} rence. For the sake of completeness, the stochastic weather generator and the downscaling method are briefly described below.

\subsection{Stochastic weather generator}

10 In this study, a day with total rainfall of $0.2 \mathrm{~mm}$ or more is considered a wet day. The process can be determined by the following conditional probabilities

$p_{01}=\operatorname{Pr}\{$ precipitation on day $t \mid$ no precipitation on day $t-1\}$

$p_{11}=\operatorname{Pr}\{$ precipitation on day $t \mid$ precipitation on day $t-1\}$

for the wet-day occurrence pattern denoted by (w/d) and (w/w), respectively. The tran15

sition matrix is completed with the other two complementary conditional probabilities for dry-day occurrence pattern $p_{00}=1-p_{01}$ (probability of no precipitation on day $t$ conditional on no precipitation on day $t-1$ ) and $p_{10}=1-p_{11}$ (probability of no precipitation on day $t$ conditional on precipitation on day $t-1$ ). Simple calculations give the unconditional wet-day probability $(\pi)$ and the first lag autocorrelation of the precipitation occurrence series $(\gamma)$ as

$\pi=\frac{p_{01}}{1+p_{01}-p_{11}}, \quad$ and $\quad \gamma=p_{11}-p_{01}$.

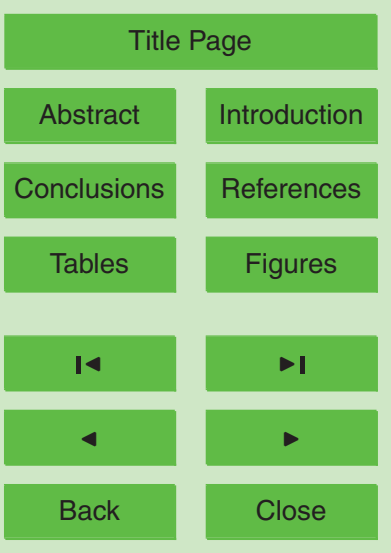

Full Screen / Esc

Printer-friendly Version

Interactive Discussion 
The daily precipitation amount $x$ on wet days is described by a Gamma distribution with probability density function

$f(x)=\frac{(x / \beta)^{\alpha-1} \exp (-x / \beta)}{\beta \Gamma(\alpha)} ; \quad \alpha, \beta>0 ;$

where $\alpha$ is the shape parameter, $\beta$ the scale parameter and $\Gamma(\alpha)$ the Gamma function. 5 The mean $(\mu)$ and variance $\left(\sigma^{2}\right)$ of the daily precipitation amount on wet days are then given by

$\mu=\alpha \beta, \quad$ and $\quad \sigma^{2}=\alpha \beta^{2}$.

Given the differences in the statistical characteristics of daily precipitation series for different months, parameterization of the weather generator should be conducted on a monthly basis. For each month, the values of $\pi$ and $\gamma$ are firstly estimated and then two daily precipitation series, one for $(\mathrm{w} / \mathrm{d})$ and the other for $(\mathrm{w} / \mathrm{w})$, are modeled separately using the parameterization by Eq. (3), resulting in the mean and corresponding variances $\mu_{01}$ and $\sigma_{01}^{2}$ for the w/d series, and $\mu_{11}$ and $\sigma_{11}^{2}$ for the w/w series. Together with $\pi$ and $\gamma$, six parameters need to be estimated for each site. With the objective function of minimizing the squared roots of differences (RMSE) between observed and generated daily precipitation series, the simplex method is employed for automatic model calibration and estimation of these parameters.

Stochastic weather generators are site-specific models, for which parameters are estimated from the observed daily data for each site. However, studies on future climate change require downscaling coarse-grid outputs to local scale. The precipitation model must be determined at the coarse GCM grids. In this study, the model parameters for the GCM grid were calculated by the areal averages of the observed stations $i=1, \cdots, N(N=17$ in our study) with consideration of the correlation between sites. Let $w_{s}$ be the weighting factors calculated by the Thiessen Polygon method (Thiessen, 25 1911; see also, for example, Okabe et al., 2000, p. 417) for site $s$ whose values are shown in Table 1 and $r_{s t}$ the correlation coefficient between daily precipitation data for
HESSD

$3,1145-1183,2006$

Downscaling of daily precipitation

Y. D. Chen et al.

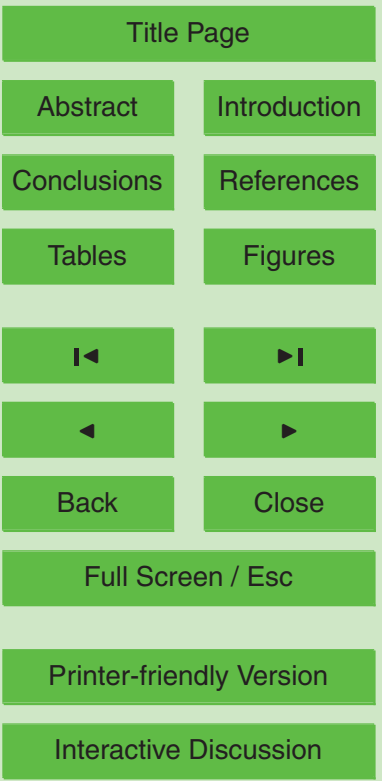

EGU 
sites $s$ and $t$. Denote by subscript $s$ the model parameters for site $s$ and by a bar on the top for the GCM (HadCM2) grid. We then have

\section{HESSD}

$\bar{p}_{01}=\sum_{s=1}^{N} w_{s} p_{01, s}, \quad \bar{p}_{11}=\sum_{s=1}^{N} w_{s} p_{11, s}$,

$\bar{\mu}=\sum_{s=1}^{N} w_{s} \mu_{s}, \quad \bar{\sigma}^{2}=\sum_{s=1}^{N} w_{s}^{2} \sigma_{s}^{2}+2 \sum_{s=1}^{N-1} \sum_{t=s+1}^{N} w_{s} w_{t} r_{s t} \mu_{s} \mu_{t}$,

5 and

$\bar{\pi}=\frac{\bar{p}_{01}}{1+\bar{p}_{01}-\bar{p}_{11}}, \quad \bar{\gamma}=\bar{p}_{11}-\bar{p}_{01}$

We will examine the validity of using areal averages in our study.

\subsection{Downscaling method}

The process of using GCM projections to produce local-scale or site-specific climate change scenarios includes two steps. Firstly, some adjustment on climate statistics at the GCM grid scale must be made to reflect the relative climate changes (Wilby et al., 1998; Wilks, 1999). Secondly, under a given climate change scenario, the extrapolated area-averaged GCM projections are disaggregated into individual sites, which is basically the meaning of downscaling. Since the first step was not involved in this study, changed-climates are assumed to be known and used for estimating stochastic precipitation model parameters for the validation of the downscaling method.

Scale issues and downscaling techniques have been extensively studied in recent years (e.g., Blöschl and Sivapalan, 1995; Wood, 1998). It is believed that both the present and future climates share statistical similarities at various scales. According to the self-similarity theory, statistical parameters of climatic series at one scale, after some kind of mathematical transformation if necessary, can be applied to another

Downscaling of daily precipitation

Y. D. Chen et al.

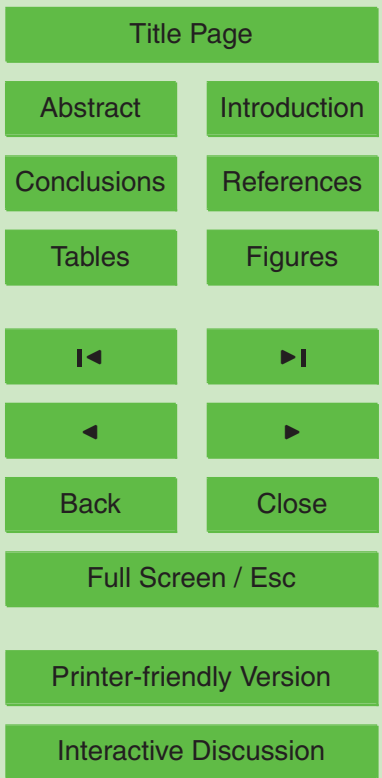

EGU 
scale through a certain scaling relationship. For the downscaling of daily precipitation, the following two relationships are normally adopted to relate the statistical parameters $F$ at the GCM scale $\left(P_{\mathrm{GCM}}\right)$ to those for individual stations $\left(P_{\text {station }}\right)$ :

5 (A1) $F$ (future $\left.P_{\mathrm{GCM}}\right)-F$ (present $\left.P_{\mathrm{GCM}}\right)=F$ (future $\left.P_{\text {station }}\right)-F$ (present $P_{\text {station }}$ ), indicating that the absolute changes in parameter values after some kind of functional transformation $F$ are identical at different scales; and

(A2) (future $\left.P_{\mathrm{GCM}}\right) /\left(\right.$ present $\left.P_{\mathrm{GCM}}\right)=$ (future $\left.P_{\text {station }}\right) /\left(\right.$ present $P_{\text {station }}$ ), indicating 10 that the relative changes in parameter values induced by climate change are the same at different scales.

In this study, the first relationship was applied to the probabilities $\pi$ with log-odds transformation $L(\pi)$ and $\gamma$ with the Fischer Z-transformed autocorrelations $Z(\gamma)$ defined respectively by

$L(\pi)=\ln [\pi /(1-\pi)] \quad$ and $\quad Z(\gamma)=0.5 \ln [(1+\gamma) /(1-\gamma)]$

The second assumption was applied to the other two model parameters $\mu$ and $\sigma^{2}$.

For the baseline climate, let $\left(\pi_{s}, \gamma_{s}, \mu_{s}, \sigma_{s}^{2}\right)$ be the parameters for individual stations and therefore the area-average parameters $\left(\bar{\pi}, \bar{\gamma}, \bar{\mu}, \bar{\sigma}^{2}\right)$ can be calculated using Eqs. (5-7). Given the GCM-generated areal average parameter set $\left(\bar{\pi}_{\mathrm{GCM}}, \bar{\gamma}_{\mathrm{GCM}}\right.$, 20 $\bar{\mu}_{\mathrm{GCM}}, \bar{\sigma}_{\mathrm{GCM}}^{2}$ ) projected under the changed climate, the above relationships are employed to estimate the downscaled parameters $\left(\hat{\pi}_{s}, \hat{\gamma}_{s}, \hat{\mu}_{s}, \hat{\sigma}_{s}^{2}\right)$ for site $s$. Under the similarity assumptions (A1) and (A2), the downscaled parameters can be derived as

$$
\begin{aligned}
& \hat{\pi}_{s}=\frac{\exp \left[L\left(\pi_{s}\right)+L\left(\bar{\pi}_{\mathrm{GCM}}\right)-L(\bar{\pi})\right]}{1+\exp \left[L\left(\pi_{s}\right)+L\left(\bar{\pi}_{\mathrm{GCM}}\right)-L(\bar{\pi})\right]}, \quad \text { and } \\
& \hat{\gamma}_{s}=\frac{\exp \left\{2\left[Z\left(\gamma_{s}\right)+Z\left(\bar{\gamma}_{\mathrm{GCM}}\right)-Z(\bar{\gamma})\right]\right\}-1}{\exp \left\{2\left[Z\left(\gamma_{s}\right)+Z\left(\bar{\gamma}_{\mathrm{GCM}}\right)-Z(\bar{\gamma})\right]\right\}+1} .
\end{aligned}
$$

\section{HESSD}

$3,1145-1183,2006$

Downscaling of daily precipitation

Y. D. Chen et al.

Title Page

Abstract

Introduction

Conclusions

References

Tables

Figures

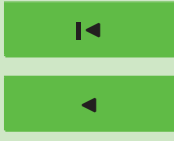

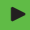

Back

Close

Full Screen / Esc

Printer-friendly Version

Interactive Discussion 
Parameter values of $\mu$ and $\sigma^{2}$, which directly determine the daily precipitation amounts, are then calculated by:

$\hat{\mu}_{s}=\mu_{s} \cdot \bar{\mu}_{\mathrm{GCM}} / \bar{\mu}$ and $\hat{\sigma}_{s}^{2}=\sigma_{s}^{2} \cdot \bar{\sigma}_{\mathrm{GCM}}^{2} / \bar{\sigma}$.

\section{Model parameterization and validation}

5 The model described in the last section includes two parts: a stochastic weather generator and a downscaling technique. It is important to evaluate its performance in the study area before simulating future precipitation under varying climate change scenarios.

4.1 Parameterization of the stochastic weather generator

Model parameters for each of the 17 stations were estimated using the observed daily precipitation series of 32 years and then these parameters were used to generate a 100-year series of daily precipitation for each station. Model parameterization was then conducted again using the generated series to produce another set of parameters. On a monthly basis, the two sets of parameters and precipitation amounts for each 15 single station as well as their areal averages were compared to evaluate the accuracy and reliability of the stochastic model given in Sect. 3.1. The results indicate that the differences in $\pi, \gamma$ and $\mu$ values and monthly precipitation amounts for the observed and the generated series are generally quite small (normally less than $10 \%$ relative errors) and the relative errors of variance $\sigma^{2}$ are larger and mostly in the range of 20$30 \%$. More specifically, relative errors of $\pi$ and $\gamma$ are the smallest (mostly less than $3 \%$ ) and seldom exceed $10 \%$ for individual stations. For mean daily precipitation amount $\mu$, the weather generator estimates its values more accurately in a relatively sense for wet days with more rainfall, as shown by the smaller errors for the continuous rainy days (the w/w situation), especially in the summer wet season. In addition, it is also found

HESSD

3, 1145-1183, 2006

Downscaling of daily precipitation

Y. D. Chen et al.

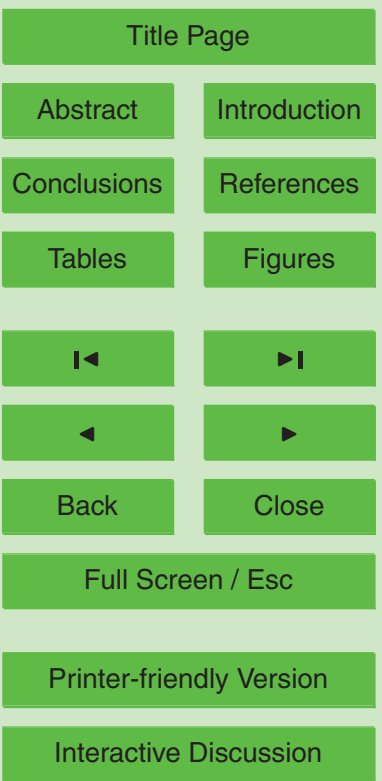

EGU 
that the variance $\sigma^{2}$ of the generated series are consistently smaller than those of the observed series for all 17 stations and, the relative errors can reach $40-50 \%$ at some stations.

The above findings can also be obtained by plotting the two sets of parameters 5 and monthly precipitation amounts in one figure for each station. As shown in Fig. 2 for Heyuan which is a major station located near the center of the study area, mean monthly parameters of $\pi, \gamma$ and $\mu$ estimated from the generated series and the generated mean monthly precipitation amounts generally match very well with the corresponding values of the observed series. For variance $\sigma^{2}$, however, parameter values of the generated series are obviously smaller than those of the observed series throughout the year. The underestimation of the observed ("interannual") variance of monthly total precipitation has also been found in previous studies, and this defect of stochastic precipitation models will need to be remedied (Gregory et al., 1993; Wilks, 1989).

The stochastic weather generator was also tested by comparing the mean monthly area-average model parameters and precipitation amounts of the generated and observed series. Similar findings can be obtained to confirm the good performance of the model. Table 2 presents the small differences between the two sets of the parameters $\pi, \gamma$ and $\mu$, as well as the underestimation of variances $\sigma^{2}$ under both $\mathrm{w} / \mathrm{d}$ and $\mathrm{w} / \mathrm{w}$ situations. Also shown in Table 2 is that the generated monthly total precipitation amounts 20 match those observed data very well for the wet season from April to September (relative errors: $0.18-2.70 \%$ and less than $1 \%$ for four months) and less satisfactory for the dry season from October to March (relative errors: $1.90-9.72 \%$ and greater than $5 \%$ for four months). It is noted that the reduced accuracy for the dry months is a result of the relatively more significant errors in the simulation of small daily precipitation amounts. For the mean annual precipitation total, the observed and generated value is $1740.4 \mathrm{~mm}$ and $1759.9 \mathrm{~mm}$, respectively, indicating a relative error of only $1.1 \%$.

Comparison between area-average and individual station values of parameters and precipitaiton amounts indicates that their monthly variations are generally similar but not always consistent. For example, as shown in Fig. 3, the monthly fluctuations of
HESSD

3, 1145-1183, 2006

Downscaling of daily precipitation

Y. D. Chen et al.

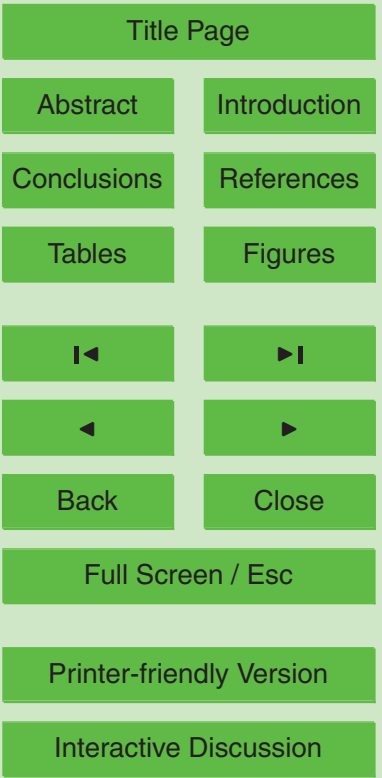

EGU 
mean daily precipitation amount $\mu$ and variance $\sigma^{2}$ for Heyuan station are usually larger than those of the area-average values, especially for the variances in summer months. This implies the heterogeneity in the spatial distribution of precipitation in the study area, which is also evidenced by the significant differences between the monthly pre5 cipitation totals for Heyuan station and the area-average values for May and June (see the lower right part of Fig. 2). Since precipitation totals are primarily controlled by the mean daily amounts, monthly variations of $P_{m}$ and $\mu$, as shown in the lower right part of Fig. 2 and the left part of Fig. 3 are very much consistent.

To further evaluate the reliability of the stochastic weather generator, spatial distribution of precipitation amounts and model parameters within the GCM grid is examined. Based on the 32-year observed daily precipitation data, Figs. 4 and 5 are drawn to show the contours of the mean monthly precipitation in June and the spatial distribution of the six model parameters for the same month, respectively. Figure 4 shows that the monsoon-driven precipitation generally decreases from south to north as the distance increases inland from the South China Sea, and precipitation peaks are roughly located at the northern end of the Pearl River Delta where the plains meet mountains in Qingyuan and Fugan counties. This spatial pattern is very much consistent with the annual precipitation distribution shown in the literature (e.g., Atlas of Natural Hazards in Guangdong, Map Publishing House of Guangdong Province, 1995). Since the monthly precipitation amounts are understandably controlled by the probabilities of rainfall occurrence and the mean daily precipitation amounts, the spatial distribution of these three quantities should be very similar. In fact, comparison of Figs. 4 with 5 indicates that: (1) the precipitation center coincides with the areas where the chances of rainfall events are the highest (Fig. 5a); (2) the mean daily precipitation amounts (Figs. $5 \mathrm{c}$ and

d), especially for those days of continuous rainfall events (w/w situation), vary within the GCM grid in a very similar fashion as the monthly totals; and (3) the interannual variations of precipitation, especially for the $\mathrm{w} / \mathrm{w}$ situation, are higher in the areas with greater amounts of precipitation (Figs. 5e and f).

\section{HESSD}

3, 1145-1183, 2006

Downscaling of daily precipitation

Y. D. Chen et al.

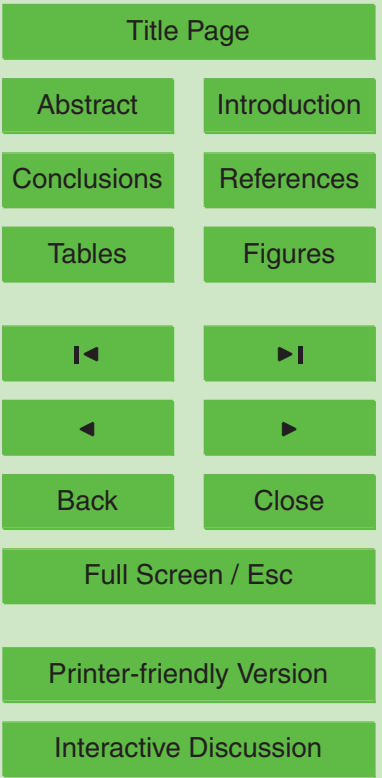

EGU 
HESSD

The downscaling procedure described in the last section is now used to disaggregate model parameters from area-averages for a GCM grid to individual sites on the ground. In order to validate this approach, two daily precipitation series for each station - one 5 for the baseline climate and the other for the assumed future climate - are used to produce the estimated and downscaled model parameters together with the precipitation amounts. In this study, the baseline series are the observed daily precipitation at the 17 stations for the 32 years. Based on a hypothetical scenario that the mean annual area-average precipitation for the GCM grid box will increase by roughly $10 \%$ in the future, observed daily precipitation data of the 16 comparatively wet years were selected to construct a changed climate series. The downscaling procedure and its validation are depicted in Fig. 6, including the following five steps: (1) precipitation model parameters were estimated for individual stations using the baseline series and then averaged for the GCM grid; (2) precipitation model parameters were estimated for indi5 vidual stations using the changed-climate series and then averaged for the GCM grid; (3) area-averaged parameters under the changed climate were downscaled to produce a set of parameters for each station; (4) the downscaled parameters were compared against those estimated from the changed-climate series to evaluate the reliability of the downscaling method; and finally (5) daily precipitation series were generated using the weather generator with the downscaled parameters and then compared against the changed climate series to validate the downscaling procedure.

The accuracy and reliability of the downscaling method are assessed by comparing the estimated and downscaled parameters under the changed climate. The relative errors of several summarized statistics between the two sets of mean monthly param$\pi, \gamma$ and $\mu$ generally fall within $10 \%$ of the corresponding values estimated directly from the precipitation series. However, the downscaling method is significantly less reliable for the variance $\sigma^{2}$ for which the relative errors fluctuate dramatically and even

Downscaling of daily precipitation

Y. D. Chen et al.

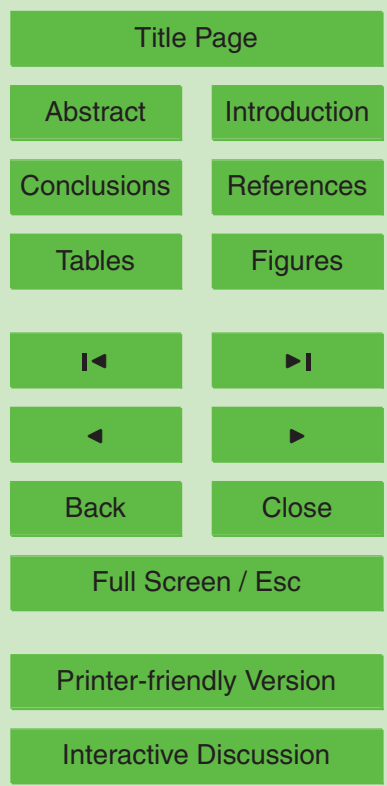

EGU 
reach several hundred percents in a few cases. This indicates that the downscaling method can accurately disaggregate areal averages of parameters $\pi, \gamma$ and $\mu$ into station-based values, but becomes less accurate for the variance $\sigma^{2}$ of precipitation amounts. The small accuracy in disaggregating station-based variance $\sigma^{2}$ of the pre5 cipitation attributes is to some extent due to the "constant ratio" assumption, i.e., A2 in Sect. 3.2. As can be seen from Fig. 7, the ratio of the precipitation statistics ( $\mu$ and $\sigma^{2}$ ) of changed climate to the present climate condition is much more stable for area average values than for station-based values. Figure 7 also shows that the ratios of $\mu$ are more consistent than those of $\sigma^{2}$. This explains why the downscaling method was 10 more accurate for $\mu$ than for $\sigma^{2}$ (see Table 3). Regarding the performance of downscaling under different weather conditions, the method is more accurate in producing the $w / w$ parameters as their relative errors averaged over all stations are obviously smaller than those for the w/d situation in almost all cases (see Table 3). This is also shown in Fig. 7 that the fluctuations in precipitation parameters throughout the year at the two 15 scales (area and station) are more consistent for continuous rainy days (w/w) than the dry-to-wet (w/d) transition.

In practice, although the accuracy of downscaling procedure for daily precipitation series at local or station scale directly determines the overall validity of projected climate change scenarios for impact studies, it is more important to compare the mean monthly and annual precipitation amounts of the changed climate series and the precipitation series generated using the downscaled parameters. As shown in Table 4 for Heyuan (the best case) and Lianxian (the worst case) and the average in the study area, the relative errors of mean monthly precipitation are normally less than $10 \%$ except for dry-season months with little precipitation which are of little concern. The two precipitation series are generally quite consistent in the wet season in terms of monthly totals, with the average relative errors ranged from $5.2-8.3 \%$ for all stations in the wet months (April to September) and 5.3-16.0\% in the dry months (October to March). With regard to the mean annual precipitation amounts, the differences between the observed and the downscaled series are minimal, with the relative errors ranging from
HESSD

3, 1145-1183, 2006

Downscaling of daily precipitation

Y. D. Chen et al.

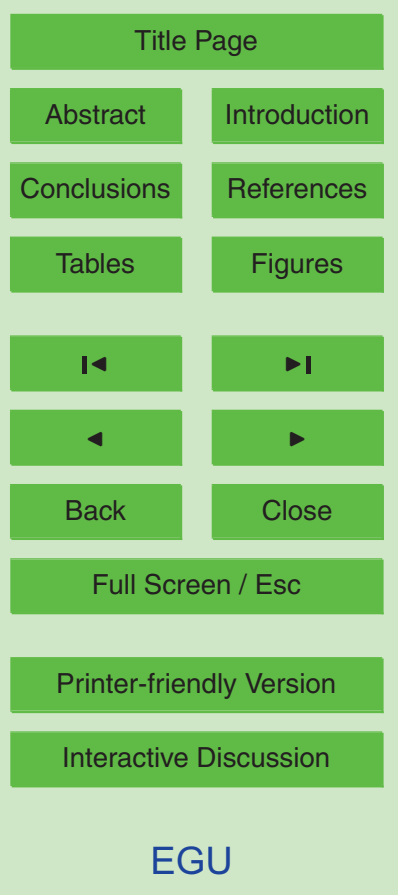


$0.2 \%$ (Heyuan) to $6.3 \%$ (Lianxian) with an average of $1.9 \%$.

The downscaling procedure was further validated by comparing the estimated and downscaled mean monthly precipitation parameters and precipitation amounts using the changed climate series. Regarding the accuracies of the downscaling procedure, 5 the above findings hold in general. As an example, Fig. 8 shows the estimated and downscaled results for Heyuan station, from which we can see the general consistencies for all months, except for the variances at some months where the two sets of parameters differ significantly from each other as demonstrated by the large relative errors in Table 3.

10 In conclusion, the method presented here works reasonably well in the study region with respect to the mean monthly and annual precipitation amounts, which are generally the main interests in climate change impact studies. We therefore will adopt the method in the next section to assess the impact of climate change on precipitation amounts at local scales.

\section{Application of the model in downscaling future precipitation}

The future changed climate data from coarse-grid GCMs are often not available daily but monthly. The statistical structure of daily precipitation series in the changed climate would not be known from the published GCM outputs. Therefore, evaluating the changes of daily statistical parameters based on available monthly precipitation amounts from GCM at the grid scale is a better approach to generating realizations of the future daily precipitation series. In this approach, we should first obtain projected future precipitation change scenarios predicted by GCMs and then establish the links between daily parameters and monthly parameters. The daily statistical parameters are adjusted on the basis of the change scenario of monthly precipitation. Lastly, the

\section{HESSD}

3, 1145-1183, 2006

Downscaling of daily precipitation

Y. D. Chen et al.

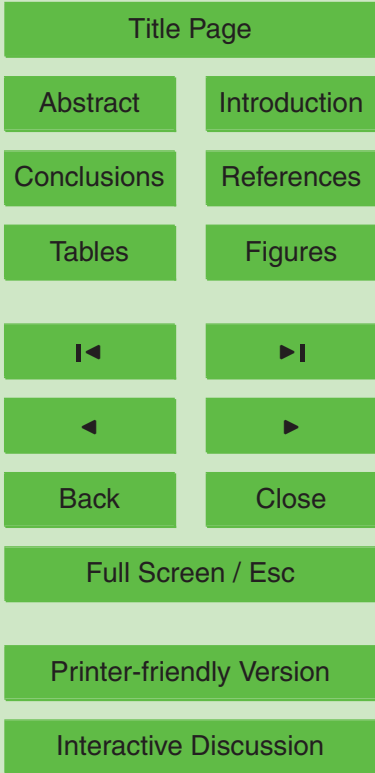

EGU 


\subsection{Projected future scenario of precipitation change}

As mentioned earlier, HadCM2 is a coupled ocean/atmosphere model used in this study. It is forced by combined $\mathrm{CO}_{2}$ and albedo (as a proxy for sulphate aerosol) changes. Table 5 lists the results of a projected future precipitation change scenario 5 over 2040-2069 or the 2050s versus present forcing scenario over 1961-1990 for the HadCM2 grid.

\subsection{Adjustment of parameters}

Once again, the daily precipitation series for the changed climate scenario will be determined by six parameters $\mu_{(\mathrm{w} / \mathrm{d})}, \sigma_{(\mathrm{w} / \mathrm{d})}, \mu_{(\mathrm{w} / \mathrm{w})}, \sigma_{(\mathrm{w} / \mathrm{w})}, \pi$ and $\gamma$. In general all six 10 parameters may change, but how they change in accord with the climate changes is difficult to know. On the basis of the projected monthly precipitation changes in the 2050s, the possible changes for parameters $\mu, \sigma$ and $\pi$ are discussed here and their influences on the generation of daily precipitation series is analyzed from the extreme value of the generation series.

15 Let $S_{N}$ be the sum of $N$ daily precipitation amounts, the mean and variance of this quantity can be written as

$\mu\left(S_{N}\right)=N \pi \alpha \beta$ and $\sigma^{2}\left(S_{N}\right) \approx N \pi \alpha \beta^{2}[1+\alpha(1-\pi)(1+\gamma) /(1-\gamma)]$,

respectively (Katz, 1983, 1985), where the approximation is for large $N$. These correspond to the average monthly precipitation and its variance, for a month comprised of $N$ days. Denote GCM grid parameters in the changed climate by prime. The ratios of the above parameters in the changed climate to those characterizing the present forcing climate gives

$$
\frac{\mu\left(S_{N}^{\prime}\right)}{\mu\left(S_{N}\right)}=\frac{\pi^{\prime} \mu^{\prime}}{\pi \mu}=\frac{\pi^{\prime} \alpha^{\prime} \beta^{\prime}}{\pi \alpha \beta} \quad \text { and } \quad \frac{\sigma^{2}\left(S_{N}^{\prime}\right)}{\sigma^{2}\left(S_{N}\right)}=\frac{\pi^{\prime} \alpha^{\prime} \beta^{2}\left[1+\alpha^{\prime}\left(1-\pi^{\prime}\right)\left(1+\gamma^{\prime}\right) /\left(1-\gamma^{\prime}\right)\right]}{\pi \alpha \beta^{2}[1+\alpha(1-\pi)(1+\gamma) /(1-\gamma)]}
$$

\section{HESSD}

3, 1145-1183, 2006

Downscaling of daily precipitation

Y. D. Chen et al.

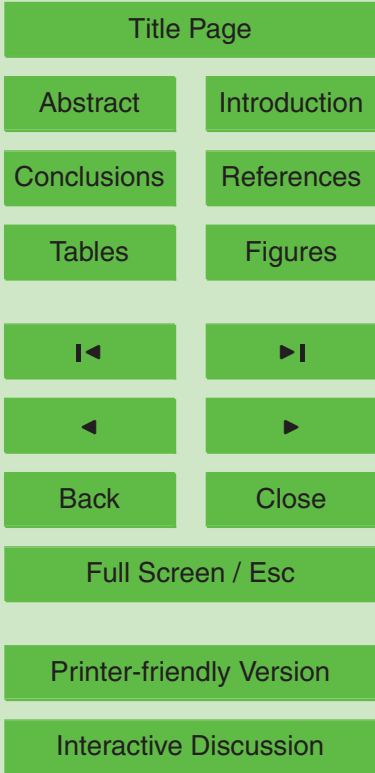


where the parameters without prime represent the values for the present climate and are known. The statistics on the left-hand side constitute the basic information describing the change of monthly precipitation amounts in question (Wilks, 1992).

For this model, the unconditional mean $\mu$ and variance $\sigma^{2}$ of daily precipitation are 5 given by

$\mu=(1-\pi) \mu_{(\mathrm{w} / \mathrm{d})}+\pi \mu_{(\mathrm{w} / \mathrm{w})}$ and $\sigma^{2}=\left[(1-\pi) \sigma_{(\mathrm{w} / \mathrm{d})}^{2}+\pi \sigma_{(\mathrm{w} / \mathrm{w})}^{2}\right]+\pi(1-\pi)\left[\mu_{(\mathrm{w} / \mathrm{w})}-\mu_{(\mathrm{w} / \mathrm{d})}\right]^{2}(13)$

(Katz, 1996). The formula to generate daily precipitation $p$ could be expressed as

$p=\mu+\sigma \varepsilon$,

where $\varepsilon$ is a Gamma distributed random variable with a range from 0 to 1 .

\subsubsection{Adjustment of mean daily precipitation $\mu$}

If the parameters $\sigma, \pi$ and $\gamma$ are kept unchanged for the changed climate, Eq. (12) ensures that the proportional change of daily precipitation $\mu$ is the same as that of monthly precipitation. In this case, the monthly precipitation from generated daily precipitation series using Eq. (14) will be also the same as that from GCMs at the grid scale. It is

simplest to assume that the conditional means of precipitation on dry and wet days are adjusted by the same amount, i.e., $\mu^{\prime}=\mu(1+k)$, both in w/d and w/w weather cases. In order to obtain the means of precipitation at the station scale, conditional means of precipitation in grid scale are then downscaled by Eq. (10). For illustrative purpose, the results of adjusted $\mu$ for the Heyaun station are shown in Table 6 .

\subsubsection{Adjustment of standard variance of daily precipitation $(\sigma)$}

Interannual variability of precipitation has been reported to change in the same direction as the mean in GCM studies (Rind et al., 1989), and consistent results are evident in observed data (Waggoner, 1989, Wilks, 1992). If the adjustment of $\mu$ is adopted
HESSD

$3,1145-1183,2006$

Downscaling of daily precipitation

Y. D. Chen et al.

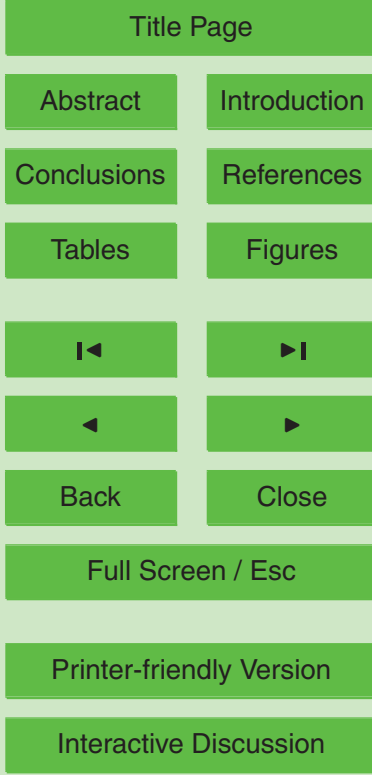

EGU 
as in Table 6, the result from Waggoner (1989) for adjusting $\sigma$ imposes the following condition

$\frac{\sigma^{2}\left(S_{N}^{\prime}\right)}{\sigma^{2}\left(S_{N}\right)}=\left[\frac{\mu\left(S_{N}^{\prime}\right)}{\mu\left(S_{N}\right)}\right]^{1.31}=k^{1.31}$,

under the assumption that other parameters are unchanged. Comparing Eqs. (12) and 5 (15) leads to

$\sigma^{\prime 2}=k^{1.31} \sigma^{2}\left(1+d \mu^{2} / \sigma^{2}\right)-d k^{2} \mu^{2}$

where $\sigma^{\prime}$ is the standard variance of the GCM grid daily precipitation in the changed climate, and $d=(1-\pi)(1+\gamma) /(1-\gamma)$.

An examination of Eq. (13) reveals that any change in the unconditional standard deviation $\sigma$ will be proportionately less than any change in the conditional standard deviations $\sigma_{(\mathrm{w} / \mathrm{d})}$ and $\sigma_{(\mathrm{w} / \mathrm{w})}$. Suppose that the changes of $\sigma_{(\mathrm{w} / \mathrm{d})}^{\prime}$ and $\sigma_{(\mathrm{w} / \mathrm{w})}^{\prime}$ are proportional to the changed climate at the grid scale, i.e., $\sigma^{\prime}=\sigma+\Delta$, in both $\mathrm{w} / \mathrm{d}$ and $\mathrm{w} / \mathrm{w}$ cases, then $\sigma_{(\mathrm{w} / \mathrm{d})}^{\prime}$ and $\sigma_{(\mathrm{w} / \mathrm{w})}^{\prime}$ can be obtained by Eqs. (13) and (16) and transferred to the station scale by downscaling Eq. (10). Table 7 shows the calculated results of $\sigma^{\prime}$ 15 for the changed climate scenario for the Heyuan station.

\subsubsection{Adjustment of daily precipitation occurrence $\pi$}

Assume that $\mu, \sigma$ and $\gamma$ are kept unchanged under the changed climate. The change of monthly precipitation due to changes of $\pi$ is predicted from HadCM2 as following. Monthly changes in precipitation will be due to $\pi$, which are predicted from HadCM2.

20 From Eqs. (11-13), we have

HESSD

3, 1145-1183, 2006

Downscaling of daily precipitation

Y. D. Chen et al.

Title Page

Abstract

Introduction

Conclusions

References

Tables

Figures

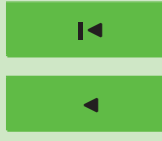

$\rightarrow 1$

Back

Close

Full Screen / Esc

Printer-friendly Version

Interactive Discussion

$$
\frac{\left.\left(1-\pi^{\prime}\right) \mu_{(\mathrm{w} / \mathrm{d})}+\pi^{\prime} \mu_{(\mathrm{w} / \mathrm{w})}\right] \pi^{\prime}}{\left[(1-\pi) \mu_{(\mathrm{w} / \mathrm{d})}+\pi \mu_{(\mathrm{w} / \mathrm{w})}\right] \pi}=\frac{N \pi^{\prime} \mu^{\prime}}{N \pi \mu}=k
$$


and

$\pi^{\prime}=\frac{-\mu_{(\mathrm{w} / \mathrm{d})}+\sqrt{\mu_{(\mathrm{w} / \mathrm{d})}^{2}+4 \pi k\left[\mu_{(\mathrm{w} / \mathrm{w})}-\mu_{(\mathrm{w} / \mathrm{d})}\right]\left\{\mu_{(\mathrm{w} / \mathrm{d})}+\pi\left[\mu_{(\mathrm{w} / \mathrm{w})}-\mu_{(\mathrm{w} / \mathrm{d})}\right]\right\}}}{2\left[\mu_{(\mathrm{w} / \mathrm{w})}+\mu_{(\mathrm{w} / \mathrm{d})}\right]}$.

HESSD

$3,1145-1183,2006$

Downscaling of daily precipitation

Y. D. Chen et al.

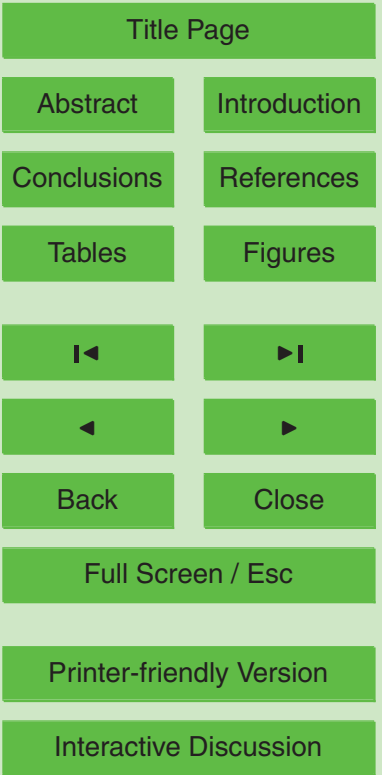

Parameter changes will influence the occurrence and amount of daily precipitation. For each adjustment of the above three parameters, a set of daily precipitation series of 200 years is generated by the stochastic model using Monto-Carlo simulation.

10 The maximum daily precipitation amount (MDP), maximum 3-day precipitation amount (M3P) and maximum 7-day precipitation amount (M7P), as well as their corresponding probability of occurrence in each month were obtained from the generated series to evaluate the significance of change of daily precipitation under the changed climate (see Figs. 9 and 10).

15 It can be seen that the change of $\mu$ and the simultaneous change of both $\mu$ and $\sigma$ increase the probabilities of occurrence of MDP, M3D and M7D in the changed climate, compared with the present climate. These increases are more significant for the larger values in the MDP, M3P and M7P series. However, only slight changes of MDP, M3P and M7P series are observed for changed $\pi$. In terms of the timing of maximum precipitation, climate change will not alter the largest probabilities of MDP, M3P and M7P occurrence in May and June. Compared to the current situation, these probabilities will increase significantly and consistently in March. For other months the changes are generally smaller and highly variable. 


\section{Discussions and conclusions}

The stochastic model for daily precipitation generation and the statistical downscaling approach for transferring statistical parameters from GCM grid scale to local scale are investigated and applied to the subtropical region in South China. Model accuracy is assessed by comparing the generated and observed daily precipitation series. Results show that model structure is generally reasonable and this downscaling approach with weather generation technique could be used in obtaining precipitation series at the smaller spatial and temporal scales. Attention should be paid to the following aspects when applying the statistical downscaling model.

1. Determination of statistical parameters on the basis of the differences of the monthly precipitation reflect interannual structure of precipitation, and is necessary for adjustment of the daily parameters in light of monthly precipitation changes.

2. Parameter adjustments for daily information on the basis of monthly results from GCMs is a better way at present, because the results from a particular GCM grid reflect broader geographic features or "consensus" changes among GCMs at the user's discretion (Wilks, 1992).

3. Although uncertainties on the changes of daily parameters exist, we may still evaluate the influences of the changed daily parameters on the daily precipitation series, especially on extreme values of the generated series, which is very important in assessing the potential impacts on hydrology, water resources utilization and environment.

Acknowledgements. The work described in this paper was fully supported by a grant from the Research Grants Council of the Hong Kong Special Administrative Region, China (Project 25 No. CUHK4188/98H). Thanks to P. Toscas and Y.-G. Wang for their helpful comments during a CSIRO internal review of the paper.

\section{HESSD}

$3,1145-1183,2006$

Downscaling of daily precipitation

Y. D. Chen et al.

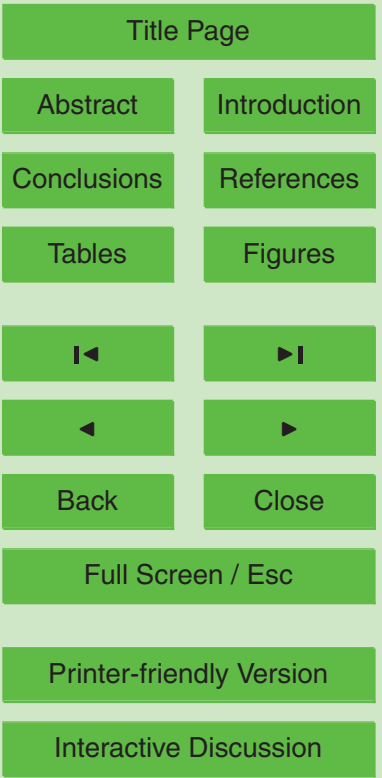

EGU 


\section{References}

Bardossy, A., Stehlik, J., and Caspary, H. J.: Automated objective classification of daily circulation patterns for precipitation and temperature downscaling based on optimized fuzzy rules, Clim. Res., 23(1), 11-22, 2002.

5 Blöschl, G. and Sivapalan, M.: Scale issues in hydrological modelling: a review, Hydrol. Processes, 9, 251-290, 1995.

Giorgi, F. and Mearns, L. O.: Approaches to the simulation of regional climate change: a review, Rev. Geophys., 29, 191-126, 1991.

Gregory, J. M., Wigley, T. M. L., and Jones, P. D.: Application of Markov models to areaaverage daily precipitation series and interannual variability in seasonal totals, Clim. Dyn., 8, 299-310, 1993.

IPCC-TGCIA: Guidelines on the Use of Scenario Data for Climate Impact and Adaptation Assessment. Version 1, prepared by: Carter, T. R., Hulme, M., and Lal, M., Intergovernmental Panel on Climate Change, Task Group on Scenarios for Climate Impact Assessment, 69 pp, 1999.

IPCC: Third Assessment Report - Climate Change 2001, IPCC/WMO/UNEP, 2001.

Katz, R. W.: Statistical procedures for making inferences about precipitation changes simulated by an atmospheric general circulation model, J. Atmos. Sci., 40, 2193-2201, 1983.

Katz, R. W.: Probabilitic models, in: Probability, Statistics, and Decision Making in the Atmospheric Sciences, edited by: Murphy, A. H. and Katz, R. W., Westview, 261-288, 1985.

Katz, R. W.: Use of conditional stochastic models to generate climate change scenarios, Clim. Change, 32, 237-255, 1996.

Liao, Y., Zhang, Q., and Chen, D.: Stochastic modeling of daily precipitation in China, J. Geogr. Sci., 14(4), 417-426, 2004.

25 Okabe, A., Boots, B., Sugihara, K., and Chiu, S. N.: Spatial Tessellations, Concept and Applications of Voronoi Diagrams, Wiley, England, 2000.

Rummukainen, M., Bergstrom, S., Persson, G., Rodhe, J., and Tjernström, M.: The Swedish Regional Climate Modelling Programme, SWECLIM: a review, Ambio, 33, 176-182, 2004.

Richardson, C. W.: Stochastic simulation of daily precipitation, temperature, and solar radiation, Water Resour. Res., 17, 182-190, 1981.

Rind, D., Goldberg, R., and Ruedy, R.: Change in climate variability in the 21 st century, Clim. Change, 14, 5-37, 1989.
HESSD

3, 1145-1183, 2006

Downscaling of daily precipitation

Y. D. Chen et al.

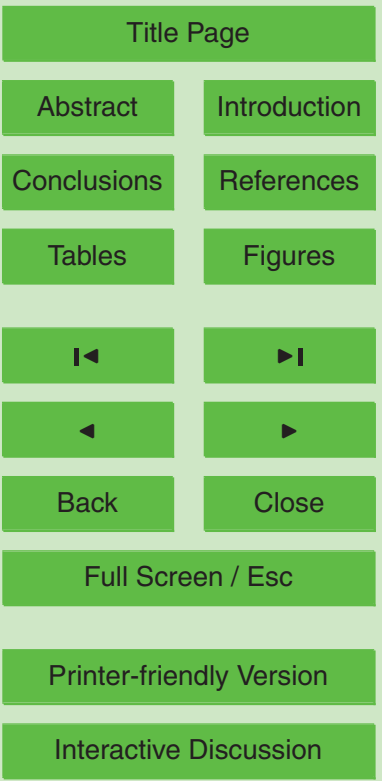


Thiessen, A. H.: Precipitation average for large areas, Mon. Wea. Rev., 39, 1082-1084, 1911.

Waggoner, P. E.: Anticipating the frequency distribution of precipitation if climate change alters its mean, Agricult. Forest Meteorol., 47, 321-337, 1989.

Wilby, R. L., Dawson, C. W., and Barrow, E. M.: SDSM - a decision support tool for the assess5 ment of regional climate change impacts, Environmental Modelling Software, 17, 145-157, 2002.

Wigley, T. M. L., Jones, P. D., Briffa, K. R., and Smith, G.: Obtaining sub-grid-scale information from coarse-resolution general circulation model output, J. Geophys. Res., 95, 1943-1953, 1990.

10 Wilby, R. L. and Wigley, T. M. L.: Downscaling general circulation model output: a review of methods and limitations, Progress in Physical Geography, 21(4), 530-548, 1997.

Wilby, R. L., Wigley, T. M. L., Conway, D., Jones, P. D., Hewitson, B. C., Main, J., and Wilks, D. S.: Statistical downscaling of general circulation model output: a comparison of methods, Water Resour. Res., 34, 2995-3008, 1998.

Wilby, R. L., Hay, L. E., Gutowski, W. J., Arritt, R. W., Takle, E. S., Pan, Z., Leavesley, G. H., and Clark, M. P.: Hydrological responses to dynamically and statistically downscaled climate model output, Geophys. Res. Lett., 27(8), 1199-1202, 2000.

Wilks, D. S.: Conditioning stochastic daily precipitation models on total monthly precipitation, Water Resour. Res., 25, 1429-1439, 1989.

Wilks, D. S.: Adapting stochastic weather generation algorithms for climate change studies, Clim. Change, 22, 67-84, 1992.

Wilks, D. S.: Multisite downscaling of daily precipitation with a stochastic weather generator, Clim. Res., 11, 125-136, 1999.

Wood, E.: Scale analyses for land-surface hydrology, in: Scale Dependence and Scale Invariance, edited by: Sposito, G., Cambridge University Press, Cambridge, 1-29, 1998.

$\mathrm{Xu}, \mathrm{C}$. Y.: From GCMs to river flow: a review of downscaling techniques and hydrologic modeling approaches, Progress in Physical Geography, 23, 229-249, 1999.

\section{HESSD}

$3,1145-1183,2006$

Downscaling of daily precipitation

Y. D. Chen et al.

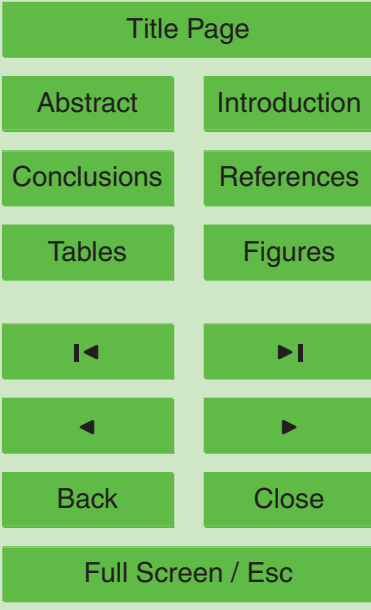

Printer-friendly Version

Interactive Discussion 


\section{HESSD}

3, 1145-1183, 2006

Table 1. Location and precipitation of stations in the study area.

\begin{tabular}{lllll}
\hline Station & Latitude $\left({ }^{\circ} \mathrm{N}\right)$ & Longitude $\left({ }^{\circ} \mathrm{E}\right)$ & $\begin{array}{l}\text { Annual mean } \\
\text { precipitation }(\mathrm{mm})\end{array}$ & Weight \\
\hline Heyuan & 23.44 & 114.41 & 1971 & 0.089 \\
Shanghang & 25.03 & 116.25 & 1504 & 0.075 \\
Meixian & 24.18 & 116.07 & 1527 & 0.031 \\
Wuhua & 23.56 & 115.46 & 1524 & 0.101 \\
Huilai & 23.02 & 116.18 & 1834 & 0.038 \\
Shanwei & 22.47 & 115.22 & 1886 & 0.071 \\
Shenzhen & 22.33 & 114.06 & 1906 & 0.034 \\
Huiyang & 23.05 & 114.25 & 1658 & 0.080 \\
Lianping & 24.22 & 114.29 & 1776 & 0.080 \\
Nanxiong & 25.08 & 114.19 & 1545 & 0.027 \\
Shaoguan & 24.48 & 113.35 & 1504 & 0.075 \\
Fogan & 23.52 & 113.32 & 2207 & 0.088 \\
Guangzhou & 23.08 & 113.19 & 1691 & 0.077 \\
Taishan & 22.15 & 112.47 & 1946 & 0.020 \\
Gaoyao & 23.03 & 112.28 & 1663 & 0.024 \\
Guangning & 23.38 & 112.26 & 1706 & 0.046 \\
Lianxian & 24.47 & 112.23 & 1582 & 0.046 \\
\hline
\end{tabular}

Downscaling of daily precipitation

Y. D. Chen et al.

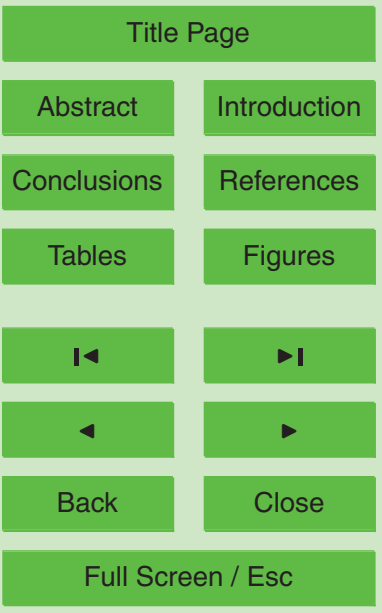

Printer-friendly Version

Interactive Discussion 


\section{HESSD}

\section{3, 1145-1183, 2006}

Downscaling of daily precipitation

Table 2. Mean monthly values of the area-average model parameters and precipitation amounts of the observed and generated daily precipitation series.

\begin{tabular}{ccccccccccccccc}
\hline \multicolumn{2}{c}{ Month } & Jan & Feb & March & April & May & June & July & Aug & Sep & Oct & Nov & Dec \\
\hline \multirow{2}{*}{$\pi$} & obs & 0.24 & 0.35 & 0.43 & 0.47 & 0.54 & 0.58 & 0.46 & 0.49 & 0.38 & 0.20 & 0.17 & 0.17 \\
& gen & 0.24 & 0.36 & 0.43 & 0.47 & 0.54 & 0.58 & 0.47 & 0.48 & 0.36 & 0.21 & 0.16 & 0.18 \\
\multirow{2}{*}{$\gamma \quad$ obs } & 0.37 & 0.40 & 0.37 & 0.33 & 0.34 & 0.36 & 0.34 & 0.33 & 0.34 & 0.38 & 0.39 & 0.39 \\
& gen & 0.39 & 0.43 & 0.38 & 0.34 & 0.34 & 0.37 & 0.37 & 0.31 & 0.34 & 0.37 & 0.39 & 0.42 \\
$\mu(\mathrm{w} / \mathrm{d})$ & obs & 4.55 & 4.67 & 7.00 & 12.15 & 13.50 & 11.72 & 11.81 & 12.35 & 11.30 & 9.09 & 6.39 & 4.55 \\
& gen & 4.73 & 4.76 & 7.10 & 12.01 & 13.40 & 11.80 & 11.95 & 12.14 & 11.38 & 9.65 & 6.76 & 5.12 \\
$\mu(\mathrm{w} / \mathrm{w})$ & obs & 7.42 & 8.86 & 9.69 & 15.55 & 19.06 & 18.37 & 15.57 & 15.82 & 15.59 & 15.23 & 10.78 & 8.07 \\
& gen & 7.38 & 8.57 & 9.41 & 15.06 & 18.38 & 17.91 & 14.96 & 15.31 & 15.10 & 15.61 & 10.65 & 8.07 \\
$\sigma^{2}(\mathrm{w} / \mathrm{d})$ & obs & 52.85 & 49.42 & 127.01 & 303.80 & 368.64 & 324.00 & 344.47 & 305.90 & 311.52 & 240.87 & 117.94 & 68.39 \\
& gen & 40.20 & 37.70 & 89.68 & 211.41 & 264.71 & 231.04 & 257.60 & 220.22 & 218.15 & 174.50 & 91.39 & 51.84 \\
$\sigma^{2}(\mathrm{w} / \mathrm{w})$ & obs & 109.83 & 123.00 & 192.93 & 434.72 & 639.58 & 664.61 & 467.42 & 474.80 & 513.02 & 540.56 & 239.63 & 142.80 \\
& gen & 77.44 & 81.36 & 123.43 & 288.66 & 432.64 & 457.96 & 307.30 & 326.52 & 334.16 & 383.38 & 164.87 & 93.90 \\
& obs & 44.3 & 76.5 & 114.2 & 199.7 & 283.1 & 288.5 & 203.5 & 223.3 & 159.5 & 74.1 & 43.3 & 30.4 \\
\hline$P m$ & gen & 46.1 & 70.9 & 116.4 & 200.7 & 286.7 & 288.0 & 209.0 & 222.3 & 160.9 & 79.9 & 45.6 & 33.4 \\
& RE & 4.23 & 7.24 & 1.90 & 0.52 & 1.29 & 0.18 & 2.70 & 0.44 & 0.87 & 7.85 & 5.18 & 9.72 \\
\hline
\end{tabular}

Y. D. Chen et al.

${ }^{*}$ Relative error in percent.

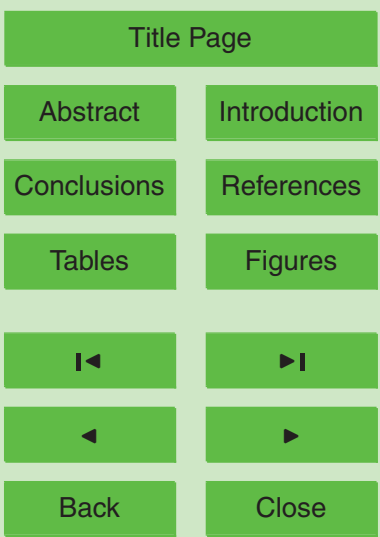

Full Screen / Esc

Printer-friendly Version

Interactive Discussion 
Table 3. Relative errors (\%) between mean monthly model parameters estimated from the changed climate series and the corresponding downscaled values for the 17 stations.

\begin{tabular}{|c|c|c|c|c|c|c|c|c|c|c|c|c|c|}
\hline \multicolumn{2}{|c|}{ Month } & Jan & Feb & March & April & May & June & July & Aug & Sep & Oct & Nov & Dec \\
\hline \multirow{4}{*}{$\pi$} & Mean & 5.87 & 2.29 & 2.63 & 2.40 & 1.21 & 3.62 & 4.93 & 2.59 & 3.05 & 5.67 & 5.35 & 10.62 \\
\hline & SD & 3.29 & 2.15 & 1.38 & 1.60 & 0.85 & 2.39 & 2.46 & 1.84 & 1.78 & 3.15 & 5.26 & 4.91 \\
\hline & Min & 0.75 & 0.07 & 0.68 & 0.10 & 0.12 & 0.12 & 0.30 & 0.06 & 0.56 & 0.93 & 0.19 & 0.37 \\
\hline & Max & 12.00 & 6.66 & 4.62 & 6.38 & 2.72 & 8.68 & 8.55 & 6.44 & 5.93 & 12.12 & 21.93 & 18.54 \\
\hline \multirow{4}{*}{$\gamma$} & Mean & 10.18 & 4.55 & 10.56 & 7.13 & 8.41 & 7.21 & 6.97 & 6.91 & 6.72 & 3.81 & 5.48 & 14.97 \\
\hline & SD & 8.38 & 4.03 & 8.02 & 4.90 & 6.88 & 5.10 & 5.90 & 3.95 & 5.00 & 3.07 & & 7.14 \\
\hline & Min & 0.00 & 0.73 & 1.19 & 1.24 & 1.74 & 0.09 & 0.83 & 1.03 & 1.25 & 0.33 & 0.01 & 4.29 \\
\hline & Max & 29.88 & 13.42 & 33.40 & 21.15 & 21.64 & 17.86 & 23.14 & 15.07 & 17.29 & 11.63 & 16.89 & 28.01 \\
\hline \multirow{4}{*}{$\mu(\mathrm{w} / \mathrm{d})$} & Mean & 9.49 & 9.14 & 7.27 & 7.40 & 10.52 & 14.97 & 11.18 & 7.83 & 7.56 & 16.62 & 12.11 & 17.80 \\
\hline & & 8.60 & 8.09 & 5.88 & 7.13 & 7.11 & 10.28 & 8.03 & 7.42 & 7.74 & 14.06 & 9. & 13.94 \\
\hline & Min & 0.16 & 0.04 & 0.95 & 0.41 & 0.05 & 0.24 & 1.19 & 0.26 & 0.43 & 0.99 & 2.05 & 1.20 \\
\hline & Max & 27.29 & 30.39 & 24.70 & 24.56 & 30.25 & 42.00 & 34.33 & 22.15 & 25.13 & 57.61 & 29.96 & 48.22 \\
\hline \multirow{4}{*}{$\mu(\mathrm{w} / \mathrm{w})$} & Mean & 6.19 & 4.98 & 8.16 & 4.62 & 5.18 & 6.41 & 3.84 & 4.96 & 6.82 & 8.01 & 7.15 & 18.76 \\
\hline & SD & 5.37 & 4.25 & 4.88 & 4.53 & 3.60 & 4.84 & 3.14 & 5.04 & 5.44 & 5.18 & 6.60 & 21.94 \\
\hline & Min & 0.28 & 0.48 & 0.97 & 0.01 & 0.06 & 0.29 & 0.04 & 0.19 & 0.53 & 2.24 & 0.53 & 1.44 \\
\hline & Max & 16.61 & 14.80 & 19.83 & 14.35 & 12.47 & 15.27 & 11.32 & 17.45 & 16.15 & 20.98 & 25.43 & 97.04 \\
\hline \multirow{4}{*}{$\sigma^{2}(\mathrm{w} / \mathrm{d})$} & Mean & 35.21 & 20.09 & 15.94 & 29.18 & 27.42 & 38.90 & 41.70 & 21.40 & 35.44 & 58.87 & 25.60 & 103.41 \\
\hline & SD & 38.80 & 24.17 & 12.84 & 28.16 & 22.20 & 41.55 & 58.66 & 23.66 & 54.52 & 69.36 & 19.22 & 118.49 \\
\hline & Min & 6.63 & 0.21 & 2.14 & 1.02 & 0.71 & 1.47 & 3.90 & 0.28 & 3.54 & 3.44 & 1.79 & 6.41 \\
\hline & Max & 147.1 & 89.9 & 53.2 & 108.3 & 74.1 & 128.0 & 203.3 & 67.8 & 241.5 & 233.3 & 66.3 & 358.1 \\
\hline \multirow{4}{*}{$\sigma^{2}(w / w)$} & Mean & 14.06 & 19.11 & 8.90 & 21.78 & 11.67 & 30.41 & 17.61 & 14.03 & 21.69 & 19.21 & 23.78 & 69.90 \\
\hline & SD & 9.91 & 22.10 & 7.65 & 10.92 & 10.13 & 12.62 & 14.21 & 14.63 & 18.53 & 17.48 & 23.83 & 121.34 \\
\hline & Min & 3.60 & 0.47 & 0.09 & 4.80 & 0.43 & 4.27 & 0.07 & 0.64 & 0.03 & 1.19 & 1.66 & 3.12 \\
\hline & Max & 37.32 & 79.12 & 24.30 & 39.65 & 38.02 & 46.81 & 51.62 & 57.37 & 66.95 & 64.67 & 96.47 & 529.28 \\
\hline
\end{tabular}

HESSD

$3,1145-1183,2006$

Downscaling of daily precipitation

Y. D. Chen et al.

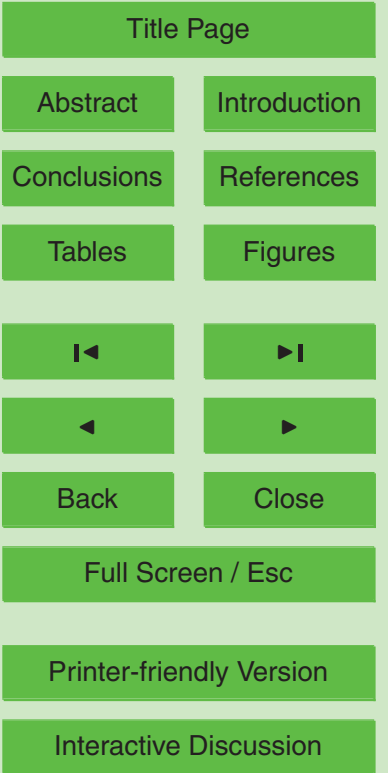




\section{HESSD}

$3,1145-1183,2006$

Downscaling of daily precipitation

Y. D. Chen et al.

Table 4. Mean monthly and annual precipitation amounts $(\mathrm{mm})$ of observed and downscaled series for the changed climate, as well as their relative errors (RE) for Heyuan (with the least relative errors), Lianxian (with the largest relative error) and for the average of 17 stations.

\begin{tabular}{ccccccccccccccc}
\hline \multicolumn{2}{c}{ Month } & Jan & Feb & March & April & May & June & July & Aug & Sep & Oct & Nov & Dec & Total \\
\hline \multirow{4}{*}{ Heyuan } & Obs & 57.2 & 124 & 174 & 251 & 382 & 379 & 223 & 260 & 165 & 61.9 & 51.0 & 26.4 & 2154 \\
& Down & 49.5 & 108 & 169 & 258 & 394 & 409 & 219 & 239 & 161 & 66.7 & 44.6 & 33.2 & 2150 \\
& RE (\%) & 13.5 & 13.0 & 2.9 & 2.6 & 3.2 & 7.9 & 1.7 & 8.1 & 2.3 & 7.6 & 12.5 & 25.4 & 0.2 \\
& Obs & 65.1 & 110 & 178 & 251 & 312 & 242 & 151 & 193 & 96.9 & 75.9 & 66.1 & 50.3 & 1791 \\
\multirow{4}{*}{ Lianxian } & Down & 62.8 & 104 & 174 & 245 & 302 & 219 & 150 & 164 & 87.1 & 77.0 & 62.1 & 33.0 & 1678 \\
& RE (\%) & 3.6 & 5.9 & 2.2 & 2.2 & 3.5 & 9.7 & 1.0 & 14.9 & 10.0 & 1.4 & 6.0 & 34.4 & 6.3 \\
\multicolumn{1}{l}{ Average RE (\%) } & 7.8 & 10.6 & 5.3 & 5.4 & 5.5 & 6.9 & 6.0 & 5.2 & 8.3 & 7.2 & 12.6 & 16.0 & 1.9 \\
\hline
\end{tabular}

\section{Title Page}

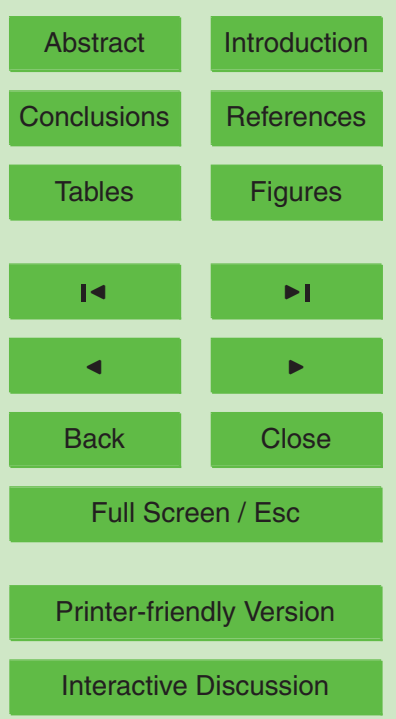




\section{HESSD}

3, 1145-1183, 2006

\section{Downscaling of daily} precipitation

Y. D. Chen et al.

\section{Title Page}

Table 5. Projected future precipitation change scenario over 2040-2069 or the 2050s vs. present forcing scenario over 1961-1990 in study grid from HadCM2.

\begin{tabular}{cccccccccccccc}
\hline \multicolumn{2}{c}{ Month } & Jan & Feb & March & April & May & June & July & Aug & Sep & Oct & Nov & Dec \\
\hline \multirow{2}{*}{ Present } & $\mathrm{P}(\mathrm{mm} / \mathrm{d})$ & 1.57 & 2.69 & 3.74 & 6.76 & 9.18 & 9.65 & 6.58 & 7.49 & 5.24 & 2.96 & 1.59 & 1.06 \\
\multirow{2}{*}{ Changed } & $\Delta \mathrm{P}(\mathrm{mm} / \mathrm{d})$ & -0.13 & 0.12 & 2.26 & 0.42 & 1.88 & 1.11 & -0.54 & -0.18 & -0.73 & 0.13 & -0.25 & -0.21 \\
& $\mathrm{k}(\%)$ & -8.11 & 4.46 & 60.4 & 6.21 & 20.5 & 11.5 & -8.25 & -2.40 & -13.8 & 4.48 & -15.9 & -19.4 \\
\hline
\end{tabular}

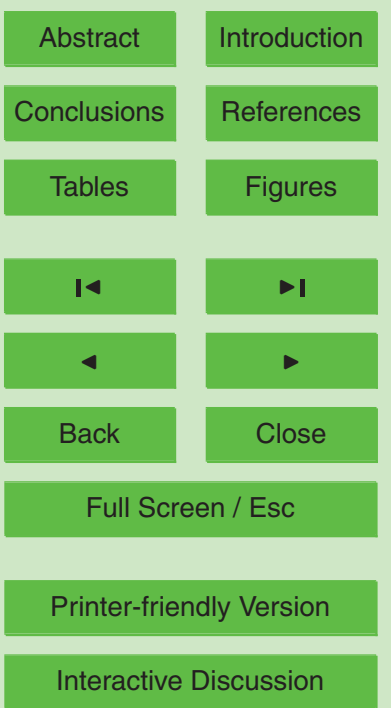

EGU 


\section{HESSD}

3, 1145-1183, 2006

Downscaling of daily precipitation

Table 6. Mean of daily precipitation in the changed climate at Heyuan.

\begin{tabular}{|c|c|c|c|c|c|c|c|c|c|}
\hline \multirow{3}{*}{ Month } & \multirow{3}{*}{$\mathrm{K}(\%)$} & \multicolumn{4}{|c|}{$\mu(\mathrm{w} / \mathrm{d})$} & \multicolumn{4}{|c|}{$\mu(\mathrm{w} / \mathrm{w})$} \\
\hline & & \multicolumn{2}{|c|}{ Grid } & \multicolumn{2}{|c|}{ Heyaun } & \multicolumn{2}{|c|}{ Grid } & \multicolumn{2}{|c|}{ Heyuan } \\
\hline & & Present & Changed & Observed & Changed & Present & Changed & Observed & Changed \\
\hline Jan & -8.11 & 4.55 & 4.18 & 5.09 & 4.67 & 7.42 & 6.82 & 8.68 & 7.97 \\
\hline Feb & 4.46 & 4.67 & 4.88 & 5.89 & 6.16 & 8.86 & 9.25 & 10.39 & 10.85 \\
\hline March & 60.35 & 7.00 & 11.22 & 7.87 & 12.61 & 9.69 & 15.54 & 10.49 & 16.82 \\
\hline April & 6.21 & 12.15 & 12.90 & 13.62 & 14.47 & 15.55 & 16.52 & 17.74 & 18.84 \\
\hline May & 20.48 & 13.50 & 16.27 & 10.90 & 13.13 & 19.06 & 22.96 & 22.85 & 27.53 \\
\hline June & 11.45 & 11.72 & 13.06 & 9.56 & 10.66 & 18.37 & 20.47 & 23.40 & 26.07 \\
\hline July & -8.25 & 11.81 & 10.84 & 10.67 & 9.79 & 15.57 & 14.29 & 14.40 & 13.21 \\
\hline Aug & -2.40 & 12.35 & 12.05 & 11.73 & 11.45 & 15.82 & 15.44 & 14.91 & 14.55 \\
\hline Sep & -13.84 & 11.30 & 9.74 & 12.56 & 10.82 & 15.59 & 13.43 & 13.35 & 11.50 \\
\hline Oct & 4.48 & 9.09 & 9.50 & 8.29 & 8.66 & 15.23 & 15.91 & 14.90 & 15.57 \\
\hline Nov & -15.88 & 6.39 & 5.38 & 7.40 & 6.22 & 10.78 & 9.07 & 12.56 & 10.57 \\
\hline Dec & -19.37 & 4.55 & 3.67 & 6.47 & 5.22 & 8.07 & 6.51 & 8.29 & 6.69 \\
\hline
\end{tabular}

Y. D. Chen et al.

Title Page

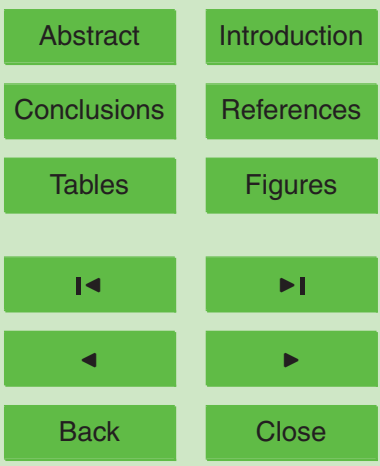

Full Screen / Esc

Printer-friendly Version

Interactive Discussion 


\section{HESSD}

$3,1145-1183,2006$

Downscaling of daily precipitation

Table 7. Standard deviation of daily precipitation in the changed climate at Heyuan.

\begin{tabular}{crrrrrrrr}
\hline & \multicolumn{3}{c}{$\sigma(\mathrm{w} / \mathrm{d})$} & \multicolumn{2}{c}{$\begin{array}{c}\text { Heyuan } \\
\text { Month }\end{array}$} & \multicolumn{2}{c}{ Grid } & \multicolumn{2}{c}{$\begin{array}{c}\text { Grid } \\
\text { Cresent }\end{array}$} & Changed & Observed & downscaled & Present & Changed & Observed & Downscaled \\
\hline Jan & 7.27 & 6.95 & 6.37 & 6.09 & 10.48 & 10.02 & 13.81 & 13.20 \\
Feb & 7.03 & 6.92 & 8.55 & 8.42 & 11.09 & 10.92 & 13.61 & 13.40 \\
March & 11.27 & 13.42 & 11.29 & 13.45 & 13.89 & 16.53 & 14.00 & 16.67 \\
April & 17.43 & 17.84 & 18.47 & 18.91 & 20.85 & 21.34 & 22.47 & 23.01 \\
May & 19.20 & 20.77 & 13.61 & 14.73 & 25.29 & 27.36 & 31.03 & 33.57 \\
June & 18.00 & 18.83 & 15.74 & 16.47 & 25.78 & 26.98 & 37.60 & 39.34 \\
July & 18.56 & 17.70 & 17.78 & 16.96 & 21.62 & 20.62 & 20.91 & 19.94 \\
Aug & 17.49 & 17.22 & 14.11 & 13.90 & 21.79 & 21.46 & 19.93 & 19.63 \\
Sep & 17.65 & 16.36 & 17.37 & 16.10 & 22.65 & 20.99 & 20.51 & 19.01 \\
Oct & 15.52 & 15.61 & 11.50 & 11.57 & 23.25 & 23.39 & 20.08 & 20.21 \\
Nov & 10.86 & 10.01 & 10.21 & 9.41 & 15.48 & 14.27 & 13.77 & 12.69 \\
Dec & 8.27 & 7.48 & 13.57 & 12.27 & 11.95 & 10.80 & 11.53 & 10.42 \\
\hline
\end{tabular}

Y. D. Chen et al.

Title Page

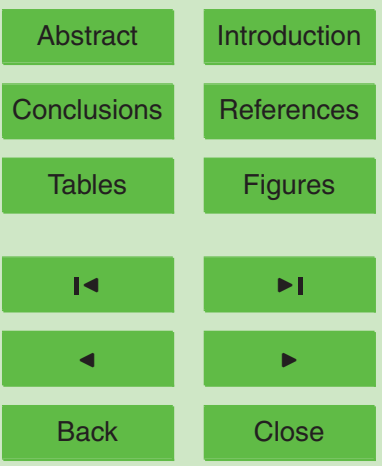

Full Screen / Esc

Printer-friendly Version

Interactive Discussion 


\section{HESSD}

3, 1145-1183, 2006

\section{Downscaling of daily} precipitation

Y. D. Chen et al.

Title Page

Table 8. Daily precipitation occurrence in the changed climate at Heyuan.

\begin{tabular}{cccccccccccccc}
\hline \multicolumn{2}{c}{ Month } & Jan & Feb & March & April & May & June & July & Aug & Sep & Oct & Nov & Dec \\
\hline \multirow{2}{*}{$\pi$-Averaged } & observed & 0.24 & 0.35 & 0.43 & 0.47 & 0.54 & 0.58 & 0.46 & 0.49 & 0.38 & 0.20 & 0.17 & 0.17 \\
& changed & 0.22 & 0.36 & 0.64 & 0.50 & 0.63 & 0.63 & 0.43 & 0.48 & 0.33 & 0.21 & 0.15 & 0.14 \\
\multirow{2}{*}{$\pi$-Heyuan } & observed & 0.22 & 0.36 & 0.47 & 0.49 & 0.61 & 0.62 & 0.49 & 0.51 & 0.39 & 0.18 & 0.15 & 0.18 \\
& changed & 0.20 & 0.37 & 0.68 & 0.52 & 0.69 & 0.67 & 0.46 & 0.50 & 0.34 & 0.19 & 0.12 & 0.15 \\
\hline
\end{tabular}

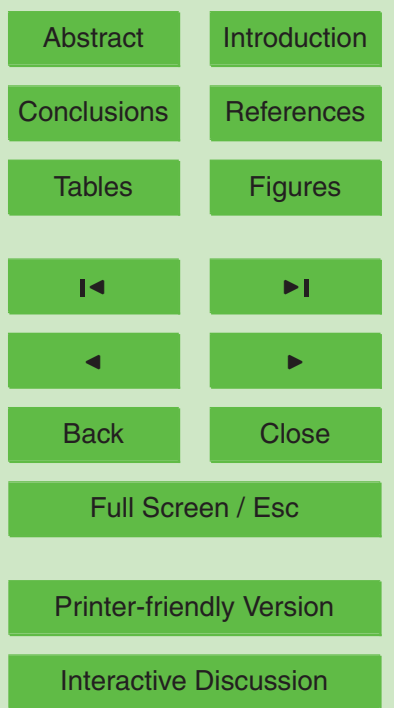

Interactive Discussion 


\section{HESSD}

3, 1145-1183, 2006

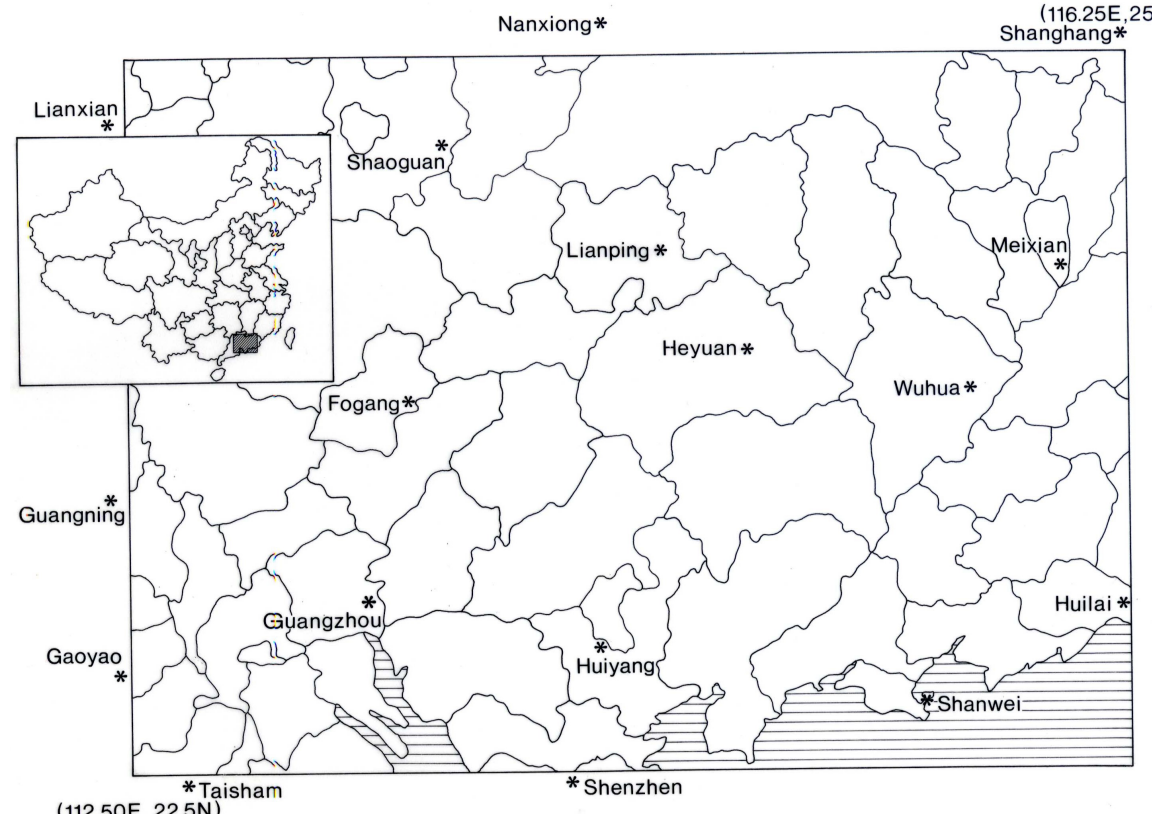

Downscaling of daily precipitation

Y. D. Chen et al.

Title Page

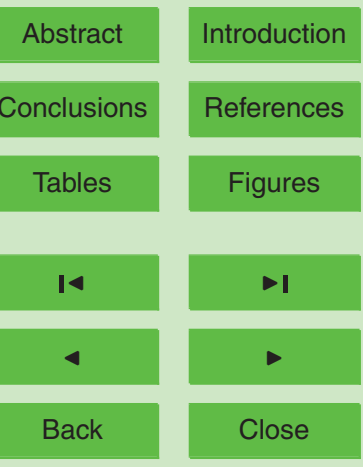

Full Screen / Esc

Printer-friendly Version

Interactive Discussion 


\section{HESSD}

3, 1145-1183, 2006
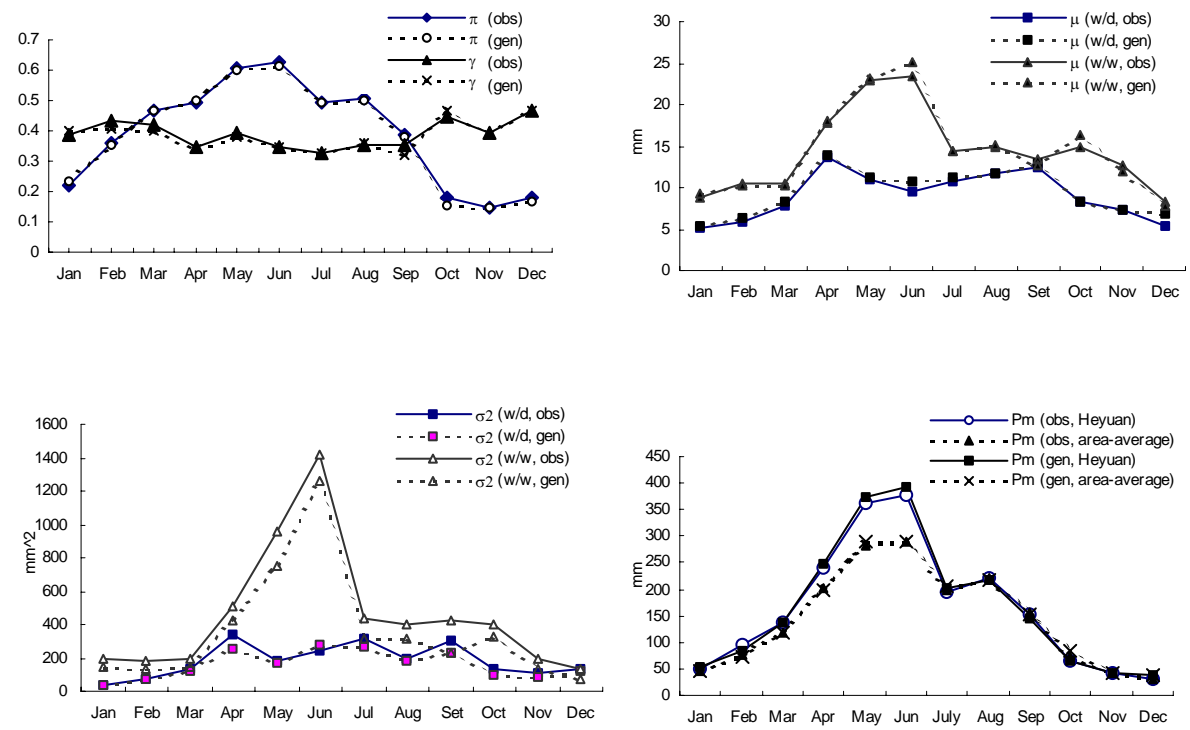

Fig. 2. Mean monthly parameters and precipitation amounts for Heyuang station and areaaverage precipitation amounts for the GCM grid box.

\section{Downscaling of daily precipitation}

\section{Y. D. Chen et al.}

\section{Title Page}

\begin{tabular}{|c|c|}
\hline Abstract & Introduction \\
\hline Conclusions & References \\
\hline Tables & Figures \\
\hline 14 & \\
\hline & \\
\hline Back & Close \\
\hline
\end{tabular}

Full Screen / Esc

Printer-friendly Version

Interactive Discussion 


\section{HESSD}

3, 1145-1183, 2006

Downscaling of daily precipitation

Y. D. Chen et al.
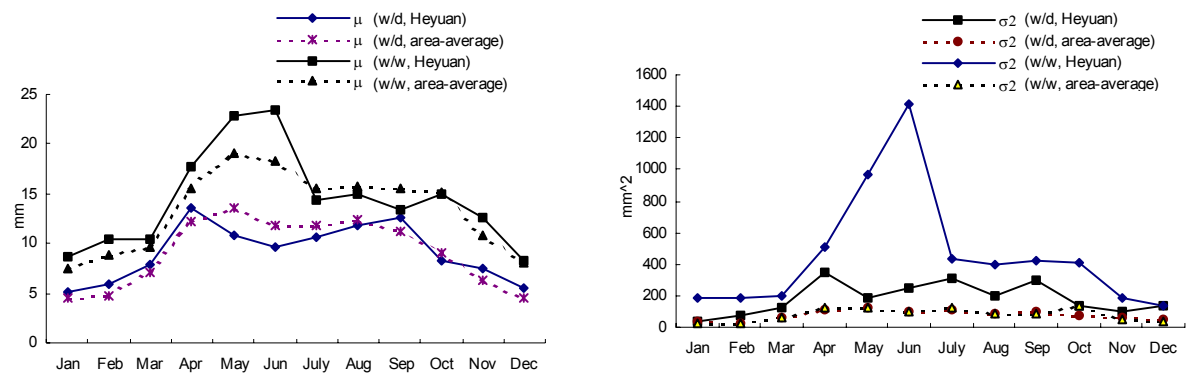

Title Page

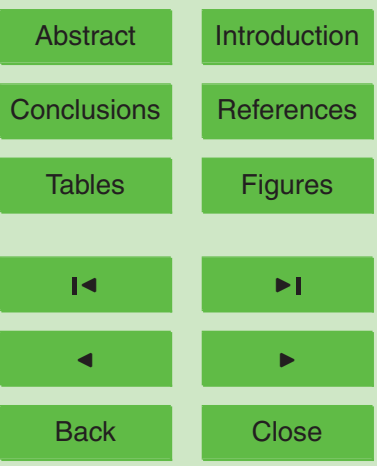

Full Screen / Esc

Printer-friendly Version

Interactive Discussion 


\section{HESSD}

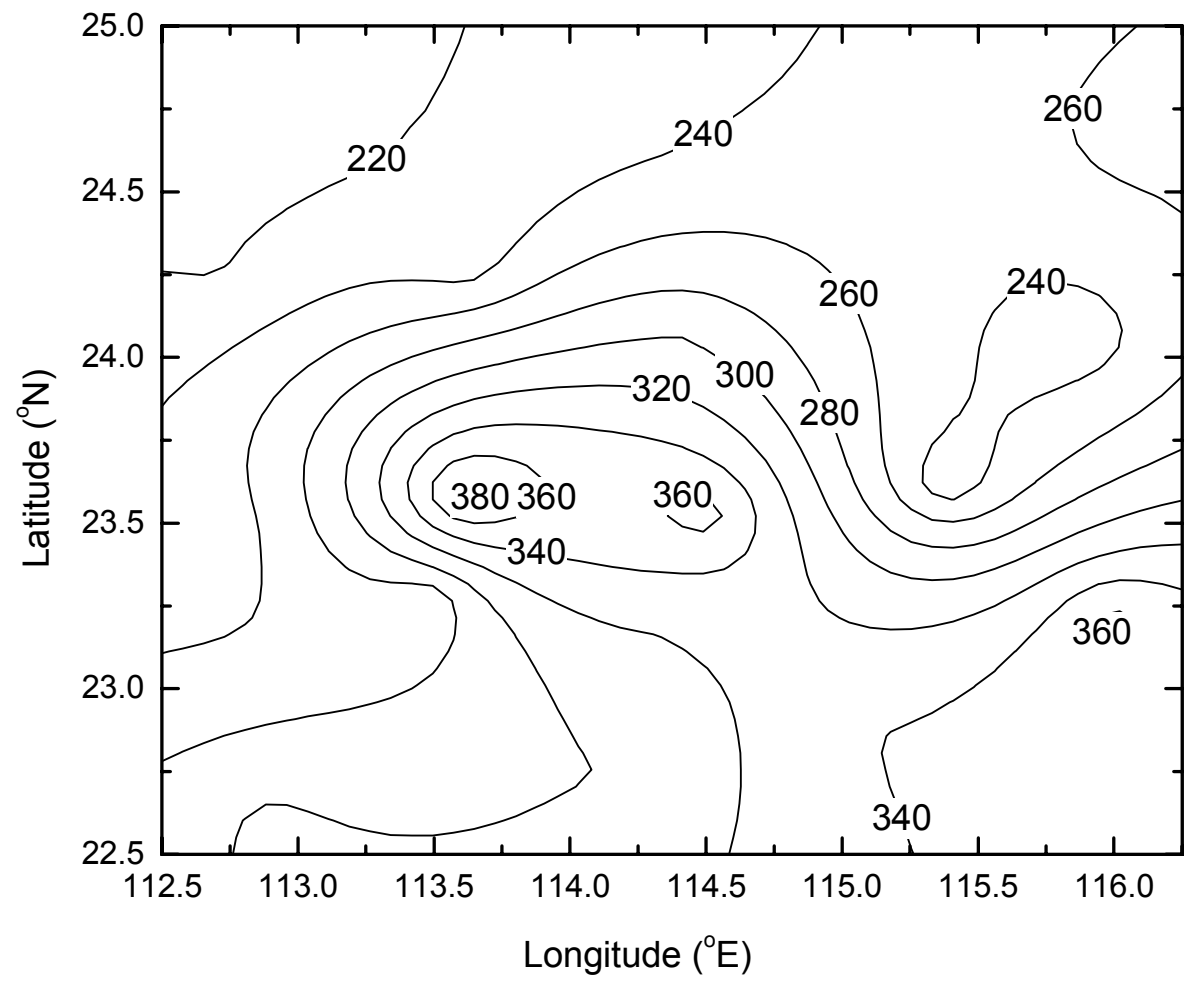

3, 1145-1183, 2006

Downscaling of daily precipitation

\section{Y. D. Chen et al.}

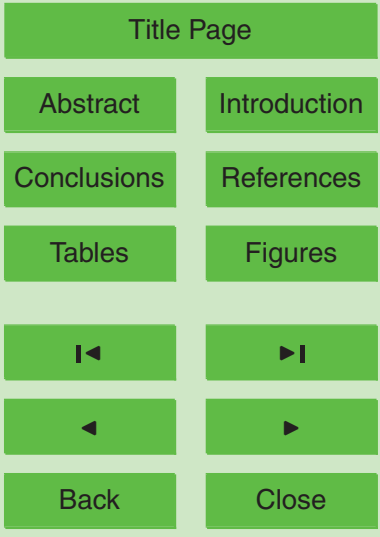

Full Screen / Esc

Printer-friendly Version

Interactive Discussion

Fig. 4. Spatial distribution of mean monthly precipitation amounts in June. 


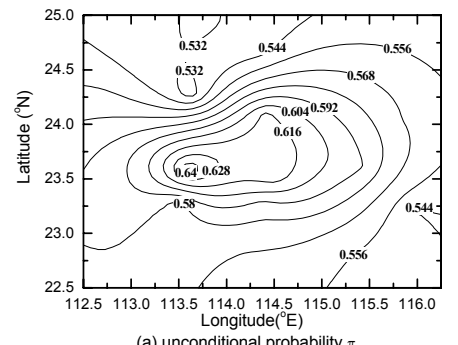

(a) unconditional probability

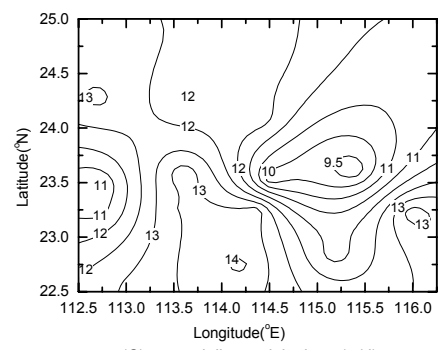

(C) mean daily precipitation $\mu(\mathrm{w} / \mathrm{d})$

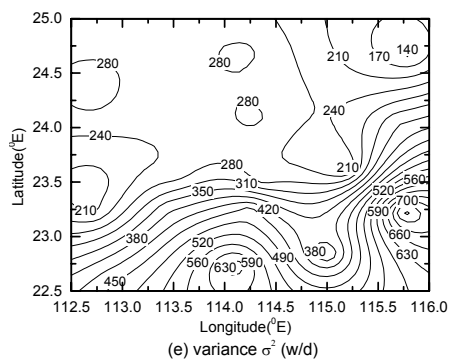

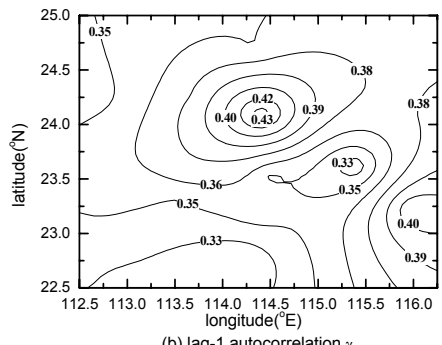

(b) lag-1 autocorrelation $\gamma$

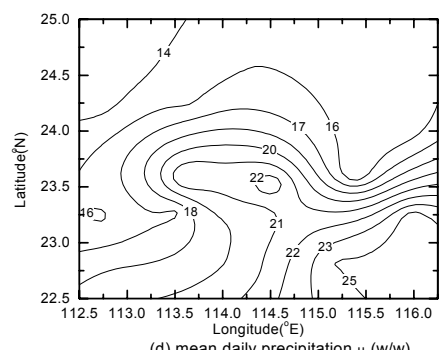

(d) mean daily precipitation $\mu(w / w)$

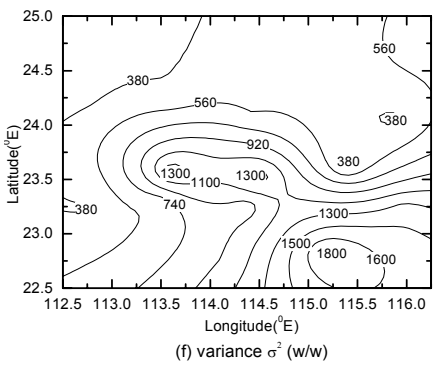

HESSD

$3,1145-1183,2006$

Downscaling of daily precipitation

Y. D. Chen et al.

Title Page

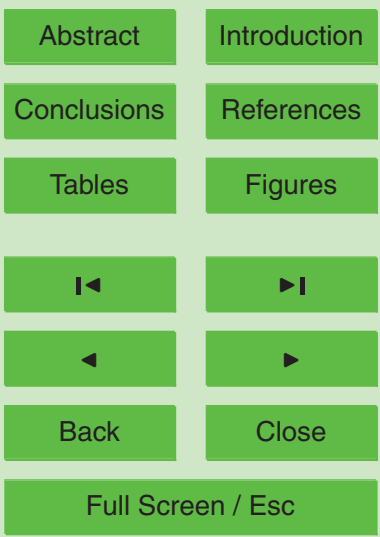

Printer-friendly Version

Interactive Discussion

Fig. 5. Spatial distribution of mean monthly precipitation model parameters in June. 


\section{HESSD}

$3,1145-1183,2006$

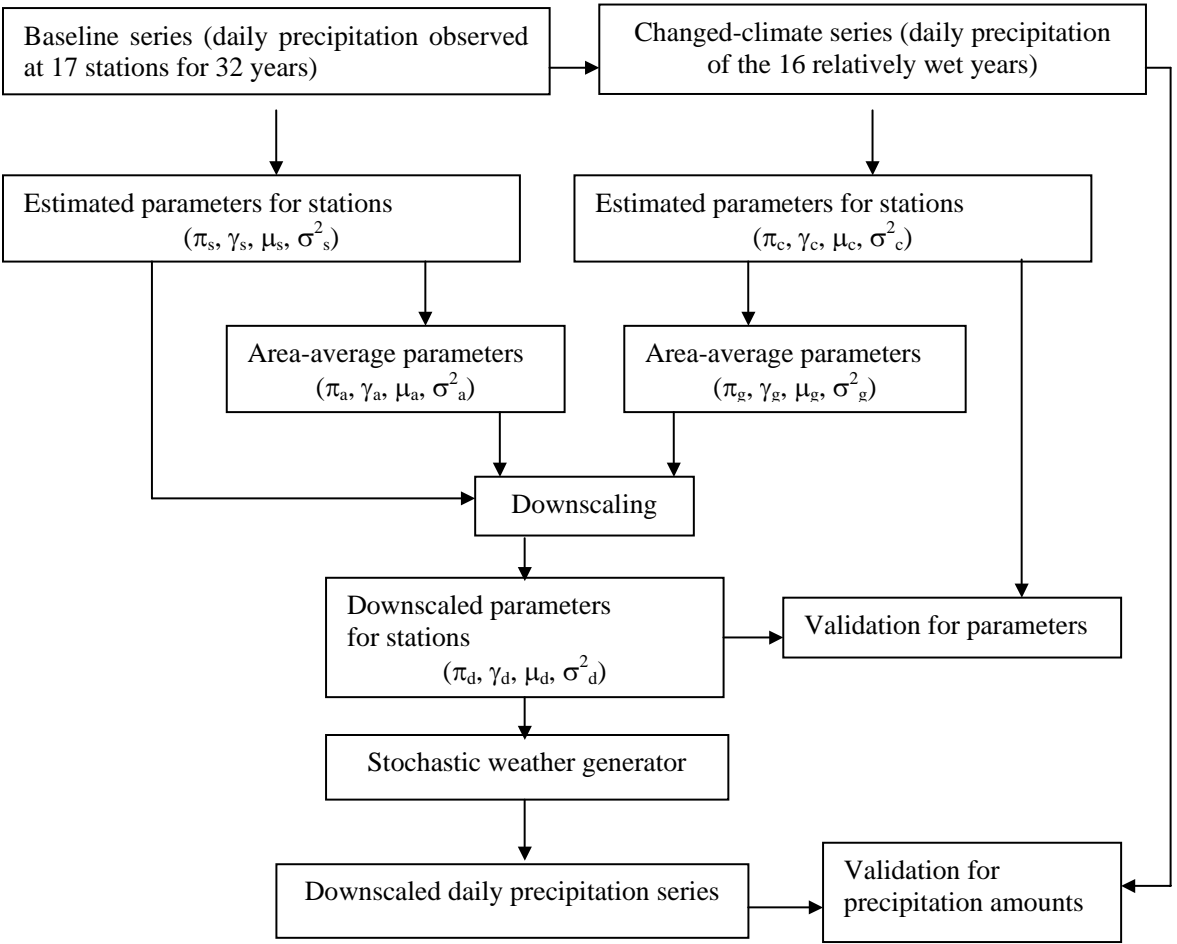

\section{Downscaling of daily precipitation}

Y. D. Chen et al.

\section{Title Page}

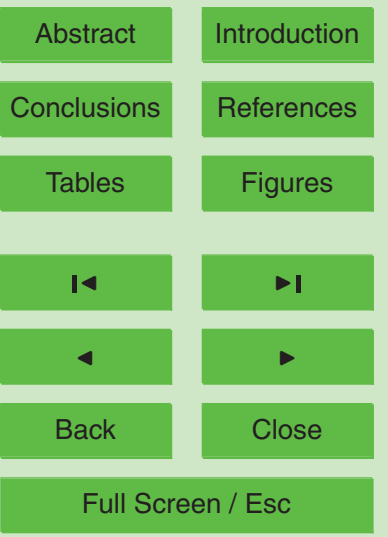

Printer-friendly Version

Fig. 6. Flow chart of the process for the validation of the downscaling procedure. 


\section{HESSD}

3, 1145-1183, 2006
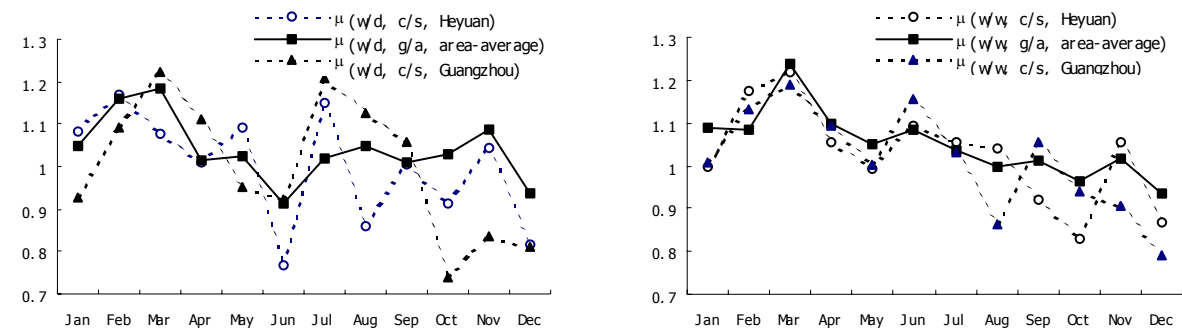

Downscaling of daily precipitation

\section{Y. D. Chen et al.}

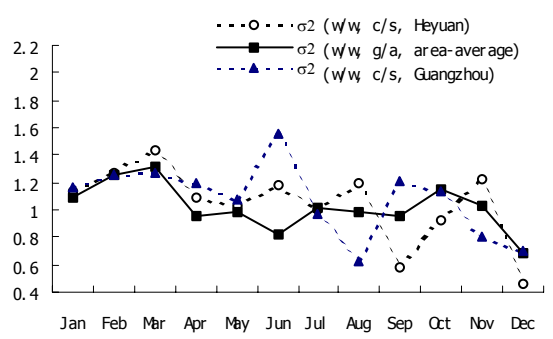

Fig. 7. Ratios of mean monthly parameters for the changed-climate series and the baseline series: single-station (c/s) vs. area-average ( $\mathrm{g} / \mathrm{a})$.
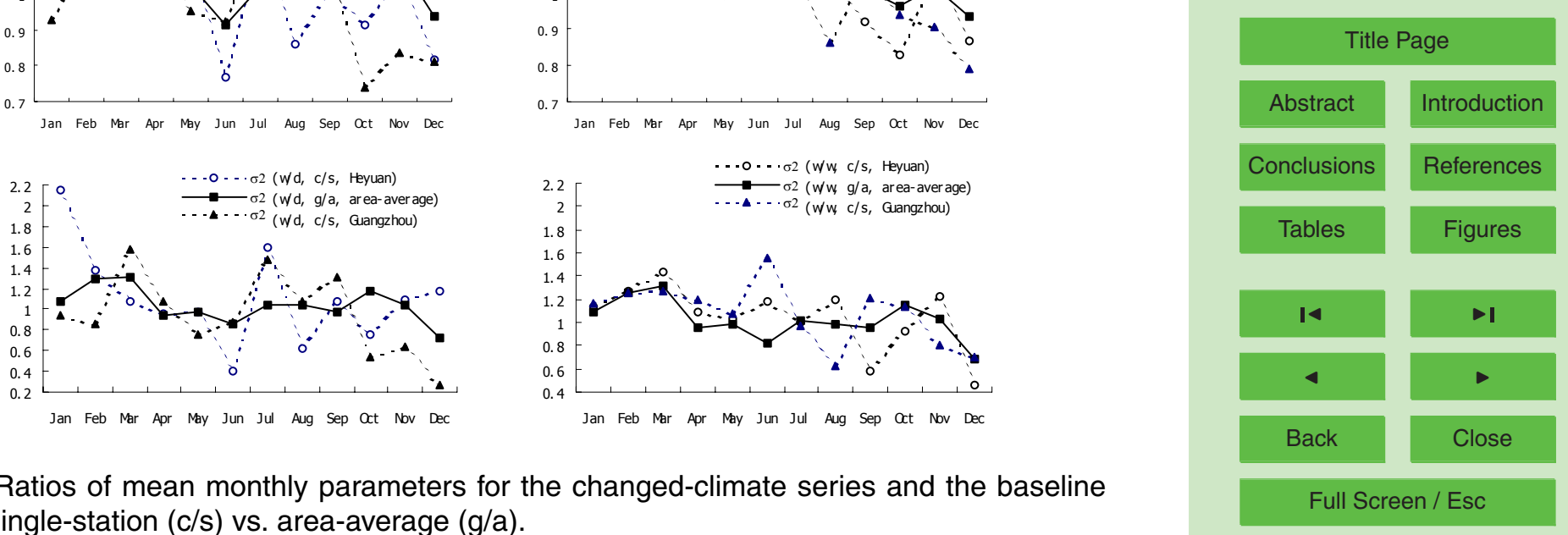

Printer-friendly Version

Interactive Discussion 


\section{HESSD}

$3,1145-1183,2006$
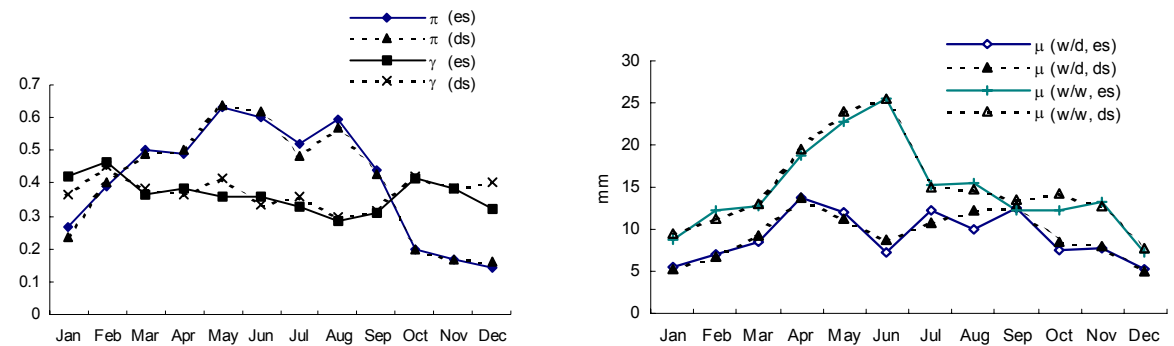

\section{Downscaling of daily precipitation}

\section{Y. D. Chen et al.}

\section{Title Page}

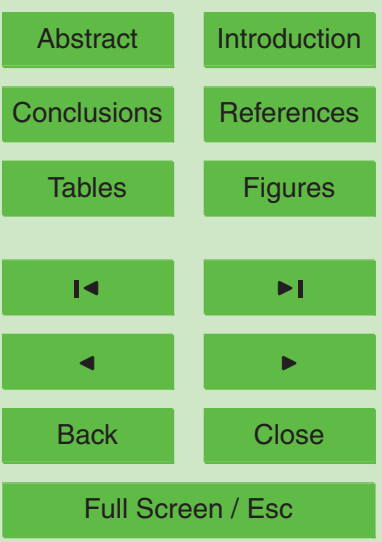

Fig. 8. Mean monthly precipitation parameters and amounts of the changed-climate series for

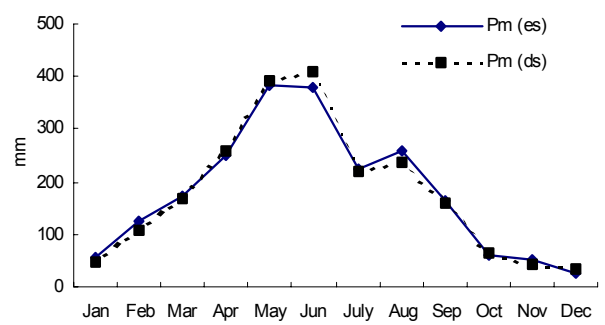

Printer-friendly Version

Interactive Discussion 

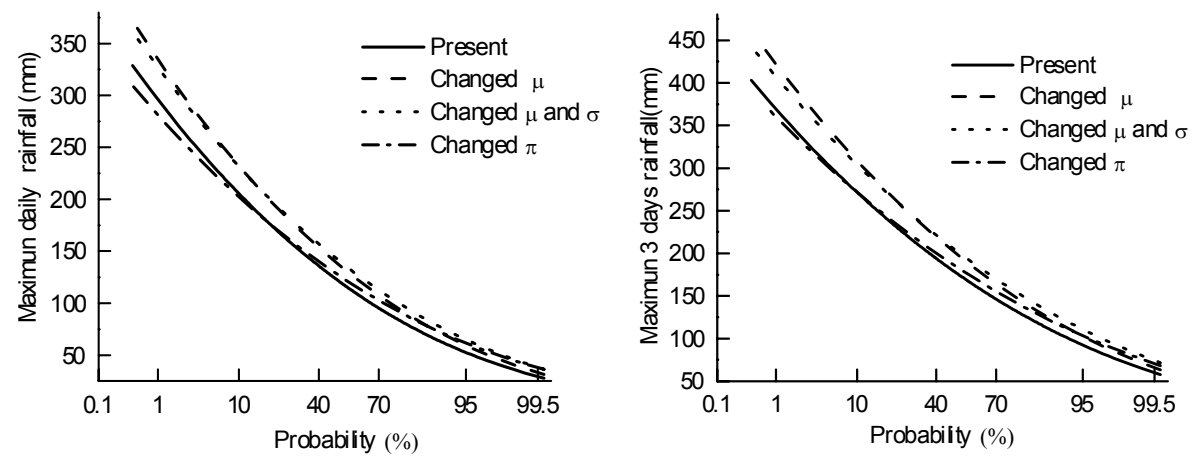

\section{HESSD}

$3,1145-1183,2006$

\section{Downscaling of daily} precipitation

\section{Y. D. Chen et al.}

Title Page

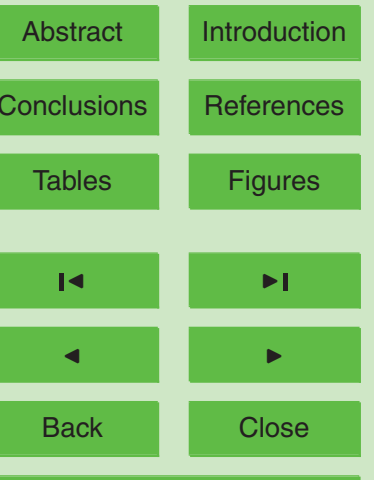

Full Screen / Esc

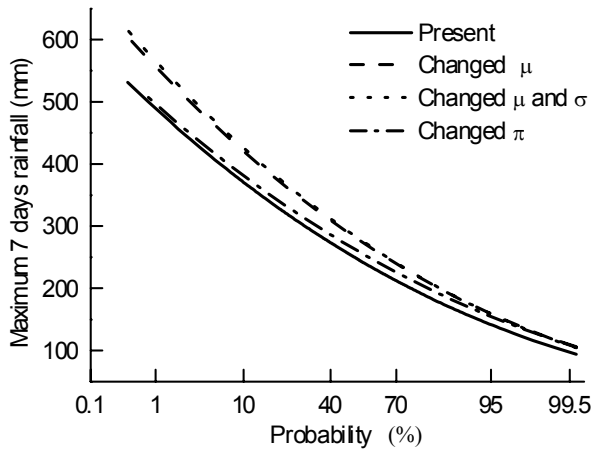

Printer-friendly Version

Fig. 9. Probability distribution curves of MDP (top-left), M3P (top-right), and M7P (bottom). 


\section{HESSD}

3, 1145-1183, 2006

Downscaling of daily precipitation
Jan Feb Mar Apr May Jun Jul Aug Sep Oct Nov Dec

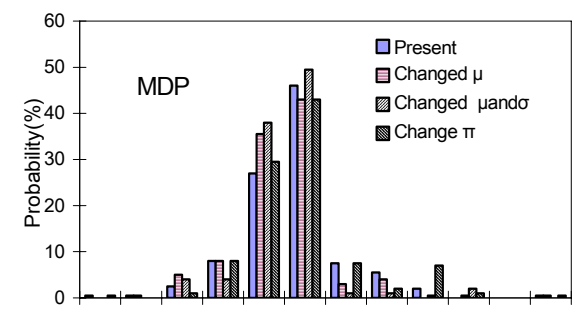

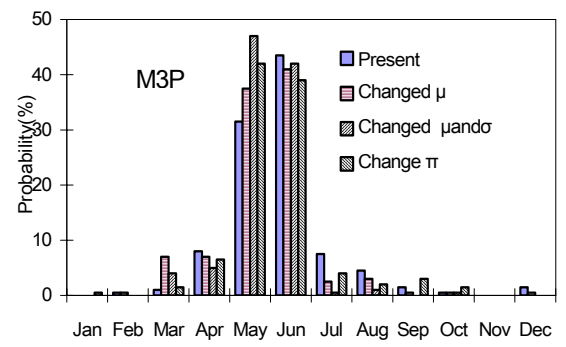

Jan Feb Mar Apr May Jun Jul Aug Sep Oct Nov Dec

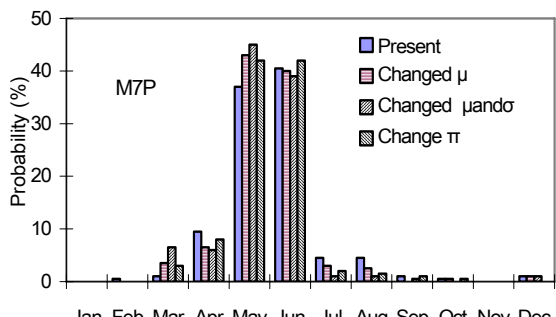

Jan Feb Mar Apr May Jun Jul Aug Sep Oct Nov Dec

Fig. 10. Probability of occurrence of MDP (top-left), M3P (top-right), and M7P (bottom) in each month.

Y. D. Chen et al.

Title Page

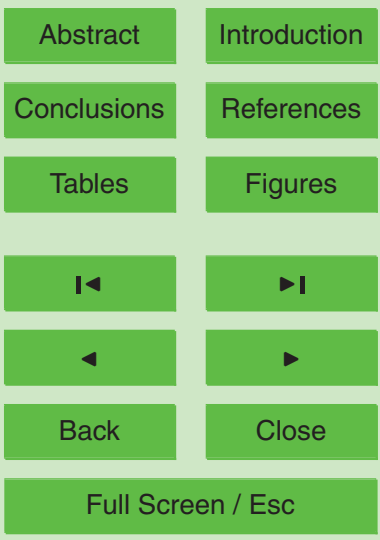

Printer-friendly Version

Interactive Discussion 